\title{
NEW METHOD OF CRITERIA WEIGHTING FOR SUPPLIER SELECTION
}

\author{
Ristono Agus \\ UPN Veteran Yogyakarta, Indonesia \\ E-mail: agus.ristono@upnyk.ac.id
}

\begin{abstract}
In the future, researchers focusing on supplier selection are likely to use a combination of multi-criteria decision-making (MCDM) methods. The analytical hierarchy process (AHP) is often used in such combinations. The function of the AHP method in MCDM is criteria weighting. When there are a relatively large number of participants involved in an evaluation judgment, it is difficult to obtain consistent opinions. In such cases, the AHP is a useful method to obtain consistent opinions over time by repeatedly conducting pairwise comparison matrices. This study proposes a new methodology to resolve such problems. In the proposed method, the decision maker assesses the level of contribution of each criterion to the selection of suppliers. Using the proposed method, comparing the contributions of these criteria to supplier selection will always produce a consistent value. The advantage of the proposed method is that decision makers do not have to assess the degree of importance of each individual criterion. So, if there are $\mathrm{n}$ criteria, the decision maker has to access as much as $n$ times. The results of this study indicate that the proposed method consistently produces a solution, without the need for repeated human judgements and without consideration of the number of criteria.
\end{abstract}

\section{KEY WORDS}

Analytic hierarchy process, comparison matrix, criteria, consistency ratio, AHP weighting.

In the selection of suppliers, companies generally have various criteria to consider. Usually, if one criterion is considered more important than other criteria, then this criterion is given greater weight. Problems arise when a supplier has to be selected based on a number of criteria [1]. In the future, researchers in the supplier selection field are likely to use a combination of methods of MCDM [2,3]. One MCDM method that is often used in such combinations is the analytic hierarchy process (AHP) $[4,5]$. Therefore, the success of the combination method is determined by AHP weighting [6].

AHP weighting can be considered valid (i.e., to have produced a consistent solution) if the consistency ratio is less than $0.1[7,8]$. The validity of AHP weighting is determined based on the consistency of the resulting pairwise comparison matrix [9]. In such cases, the ranking or weighting of criteria is based on the judgement of the decision maker [10]. The decision maker have to do (repeat) until the pairwise comparison matrix is consistent Therefore, the role of human judgment of decision makers is very important in supplier selection using the AHP method.

As the number of criteria increases, human judgments become increasingly sensitive and may become inconsistent [7]. It may be difficult to obtain consistent results when the size of the matrix is relatively large [11] or when there are more then seven criteria [12]. According to the literature, the optimum number of criteria is seven or fewer [13]. Thus, most supplier selection studies use the hierarchical method when there are multiple criteria [14]. However, the latter cannot guarantee consistent results, mainly due to inconsistency in human judgment. To address the aforementioned issues, this study proposes a new method to aid human judgment and ensure consistent decision making. The basic idea underpinning the proposed method is that decision makers are not required to draw comparisons between criteria. As noted above, the higher the number of criteria, the greater the risk of confusion among decision makers. 


\section{MATERIALS AND METHODS OF RESEARCH}

Much research has focused on overcoming inconsistencies of pairwise comparison matrices using the AHP method. The simplest and most widely performed method involves the use of hierarchical criteria (i.e., AHP criteria weighting), in which criteria are separated into different groups [15-17]. The weakness of the hierarchical method is the extended calculation time the absence of any guarantee of consistency if the number of major criteria or sub-criteria exceeds seven.

Besides the hierarchical method, researchers have described other methods to overcome inconsistencies of pairwise comparison matrices $[18,19]$. The crisp value of each criterion is included in the pairwise comparison matrix using Eq (1). In Eq (1), if the $L_{p}$ and $L_{q}$ values are equal, then the element $a_{i j}$ in the pairwise comparison matrix is $1 . L_{q}$ and $L_{p}$ represent the value of the importance of criteria $q$ and $p$. If the value of $L_{p}$ is greater than that of $L_{q}$, then the element $a_{i j}$ in the pairwise comparison matrix is $L_{p}-L_{q}+1$. If the value of $L_{p}$ is smaller than that that of $L_{q}$, then the element $a_{i j}$ in the pairwise comparison matrix is $1 /\left(L_{p}-\right.$ $\left.L_{q}+1\right)$. Inconsistency often occurs because the interval of the comparison value between the criteria is very large. Using equation $\left(L_{p}-L_{q}+1\right)$, the pairwise comparison matrix will be consistent.

$$
a_{i j}=\left\{\begin{array}{c}
1, \text { if } L_{p}=L_{q} \\
L_{p}-L_{q}+1, \text { if }\left(L_{p}-L_{q}\right)>0 \\
\frac{1}{L_{p}-L_{q}+1}, \text { if }\left(L_{p}-L_{q}\right)<0
\end{array}\right.
$$

Table 1 shows a comparison of the scales of Saaty [8] and Li et al. [19]. Replacing the crisp values $(1,3,5,7$, and 9$)$ with decimal numbers and the reverse comparison, in which $r_{i j}=1 / r_{i j}$ with $r_{i=1}=r_{i j}$ is expected to minimize inconsistencies. Disadvantages of the modified scale of Li et al. [19] is not produces accurate results.

Table 1 - Importance scale of Saaty [8] and Li et al. [19]

\begin{tabular}{|c|c|c|c|}
\hline Scale [8] & $\begin{array}{l}\text { Scale } \\
{[19]}\end{array}$ & Value & Definition \\
\hline 1 & 0.5 & Equally important & Criterion $i$ and criterion $j$ are equally important \\
\hline 3 & 0.6 & $\begin{array}{l}\text { Moderately more } \\
\text { important }\end{array}$ & Criterion $i$ is moderately more important than criterion $j$ \\
\hline 5 & 0.7 & $\begin{array}{l}\text { Strongly more } \\
\text { important }\end{array}$ & Criterion $i$ is much more important than than criterion $j$ \\
\hline 7 & 0.8 & $\begin{array}{l}\text { Very strongly more } \\
\text { important }\end{array}$ & Criterion $i$ is very much more important than than criterion $j$ \\
\hline 9 & 0.9 & $\begin{array}{l}\text { Extremely more } \\
\text { important }\end{array}$ & Criterion $i$ is extremely more important than criterion $j$ \\
\hline $\begin{array}{l}1 / 3 ; 1 / 5 \\
1 / 7 ; 1 / 9\end{array}$ & $\begin{array}{l}0.1 \\
0.2 \\
0.3 \\
0.4\end{array}$ & $\begin{array}{l}\text { Reverse } \\
\text { comparison }\end{array}$ & $\begin{array}{l}\text { If criterion } a_{i} \text { is compared with criteria } a_{j} \text { and a judgment matrix } r_{i j} \text { is } \\
\text { obtained, then the judgement matrix of } a_{j} \text { and } a_{i} \text { is as follows: } \\
\begin{array}{l}\text { - } \quad r_{j i}=1 / r_{i j}([8]) \\
\text { - } \quad r_{j i}=1-r_{i j}([19])\end{array}\end{array}$ \\
\hline
\end{tabular}

The consistency ratio in AHP is obtained first by calculating the eigenvalue maximum [20]. The consistency index is obtained by nine stages in Figure 1. Figure 1 shows the stages of the AHP. More details on the process can be found elsewhere $[8,21]$.

In Figure 1, $a_{i j}$ denote the importance assigned to different criteria ( $i$ and $\left.j\right), n$ is the number of criteria, $W_{i}$ indicates the relative weight of criterion $i . \mathrm{Cl}$ is the consistency index, and $C R$ is the consistency ratio. The $C R$ is a probability measure that the matrix is filled randomly. Thus, the $C R$ value is the ratio between the current matrix and question and answer matrix [22]. For example, $a_{12}$ denotes the importance of criteria $C_{1}$ as compared with that of $C_{2}$. This matrix aims to determine the relative importance levels of supplier selection criteria. Matrix $N_{i j}$ contains normalized $a_{i j}$ values. The data from this matrix is as an input into a relative weight matrix. The content of matrix $W_{i}$ is the result of calculating the relative 
weights of each criterion. In terms of the value $W_{i}$, the greater the value assigned to the weight of a criterion, the more this criterion is prioritized by the decision maker. The evaluation matrix $E_{i j}$ and sum matrix $V_{i}$ are the first two stages in obtaining the $\mathrm{Cl}$. To generate an evaluation matrix, $E_{i j}$, each element in matrix $a_{i j}$ is divided by the weight of the criteria $w_{i}$. To obtain the sum matrix $V_{i}$, the elements of the evaluation matrix $E_{i j}$ that are in the same row are summed. The consistency index can be obtained after calculating the eigen vector. The eigen vector is the weight of each element used for prioritizing elements at the lowest hierarchy level. After determining the consistency of the index, the results are compared using a random consistency index for each $n$ criterion. To ensure the validity of decision making, the consistency ratio should be $\leq 10 \%$ [22].

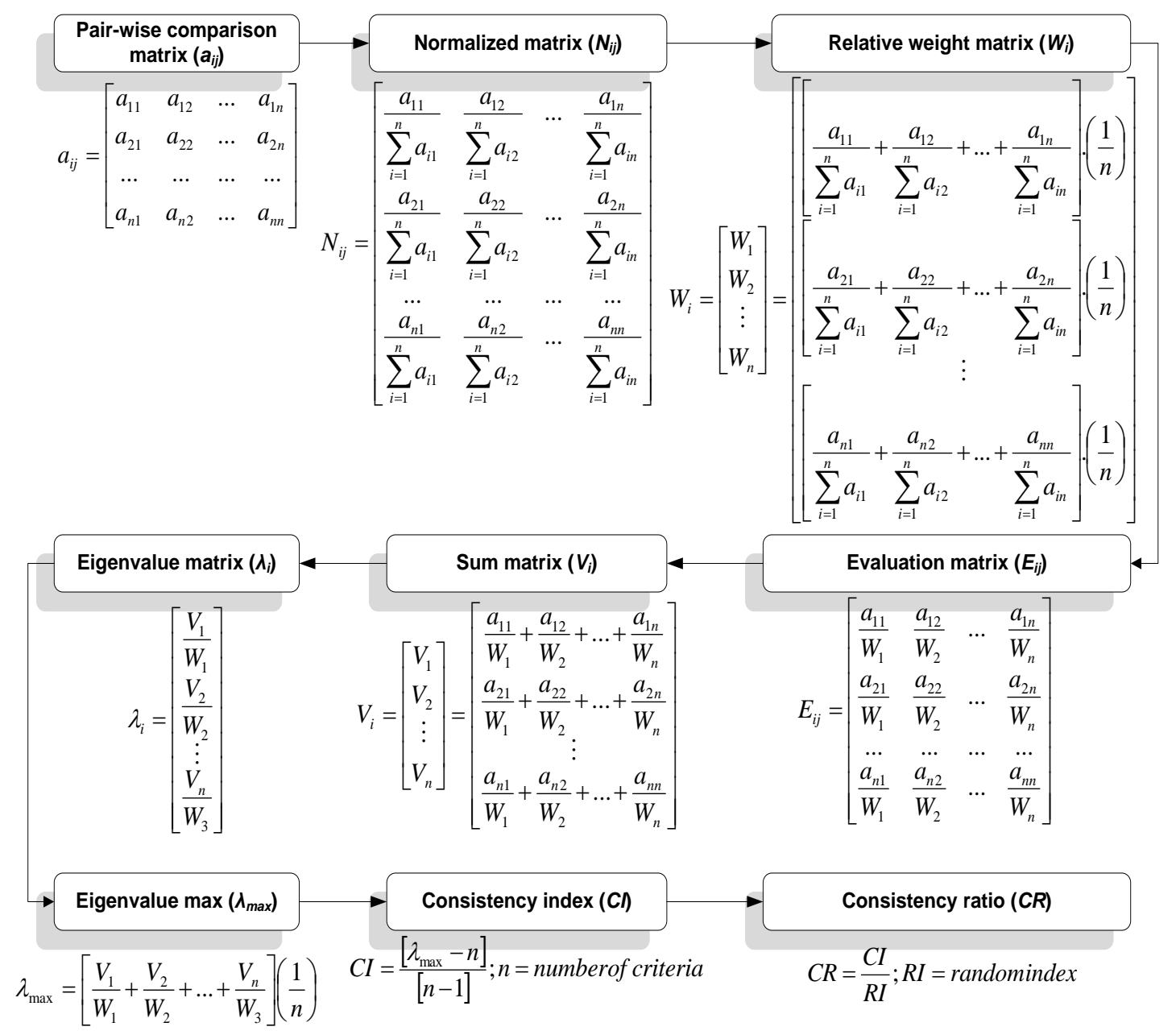

Figure 1 - The stages of the AHP

If a decision maker considers criterion $C_{2}$ to be highly important than criterion $C_{1}$ and criterion $C_{3}$ to be highly important than criterion $C_{2}$ then criterion $C_{3}$ to be highly important than criterion $C_{1}$. If $C_{2}>C_{1}$ and $C_{3}>C_{2}$, then $C_{3}>C_{1}$. Thus, $C_{3}<C_{1}$ is not possible. As shown in Appendix 1, using only three criteria, AHP will always yield an inconsistent value if pair-wise comparison matrix is inconsistent in the comparison of supplier selection criteria. Essentially, the higher the number of criteria, the higher the inconsistency. This problem can be resolved by assigning importance value to the determination of criteria. If each criterion has a fixed value, then the value assigned to the supplier selection criteria will always be fixed and consistent. If these conditions are met, then the results will always be consistent, regardless of the number of criteria.

In the proposed method, decision makers are asked to assess the level of importance (contribution) of particular criteria to supplier selection. Based on the assessment of the decision maker, supplier selection is adjusted to the level of the contribution of each criterion. 
Table 2 shows the contribution values and importance assigned to various criteria in supplier selection. Comparison of the criterion values of the decision maker results in a pairwise comparison matrix. The difference between the original AHP and the proposed method is illustrated in Figure 2. The stages of the generation of the pairwise comparison matrix using the proposed method are shown in Figure 3.

Table 2 - Values and importance assigned to various supplier selection criteria

\begin{tabular}{ll} 
Contribution level & Definition \\
\hline 1 & Weakly or slightly important \\
\hline 2 & Important \\
\hline 3 & Moderately important \\
\hline 4 & Very moderately important \\
\hline 5 & Highly important \\
\hline 7 & Very highly important \\
\hline 8 & Very very highly important \\
\hline 9 & Extremely important \\
\hline
\end{tabular}

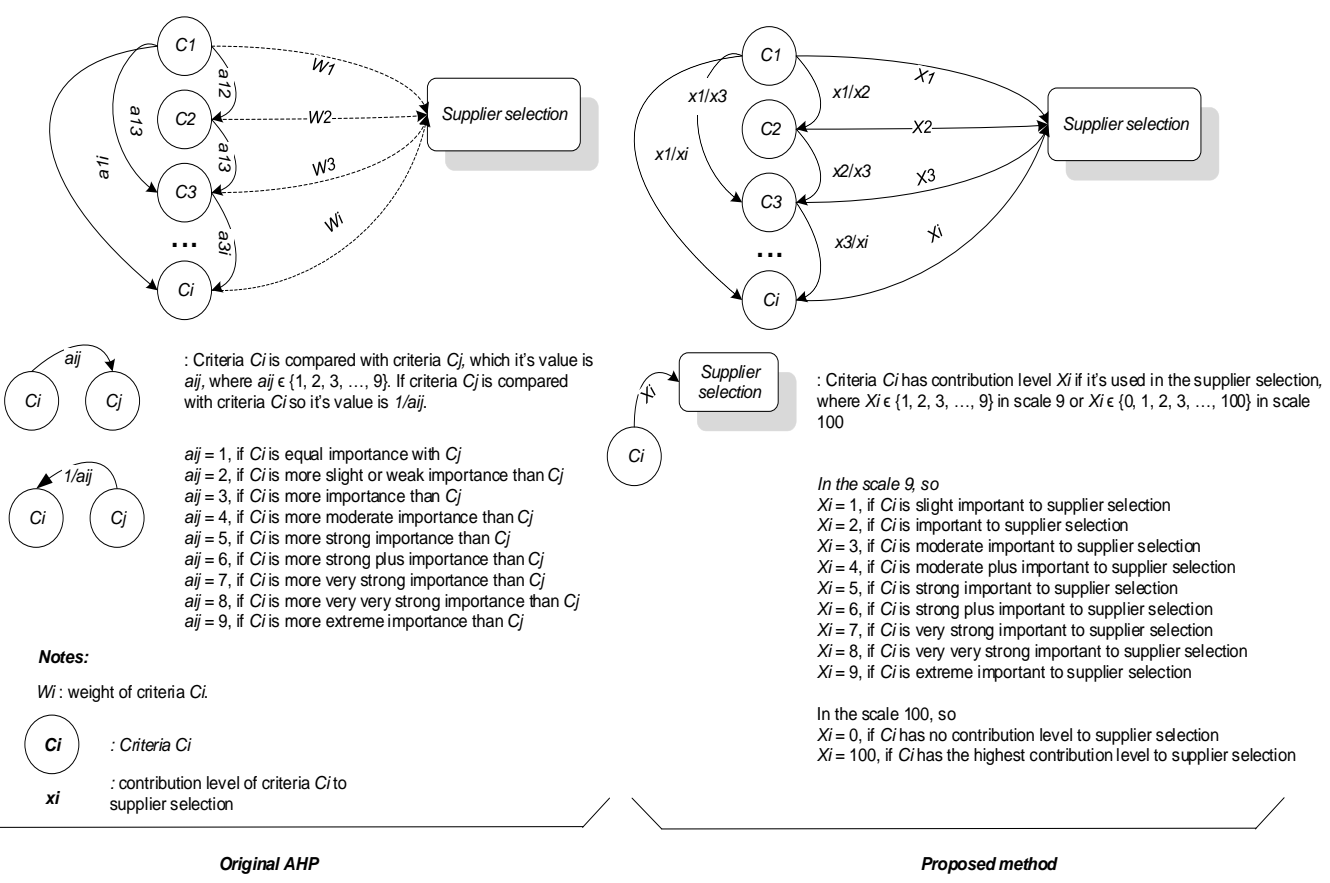

Figure 2 - Basic idea of the proposed method

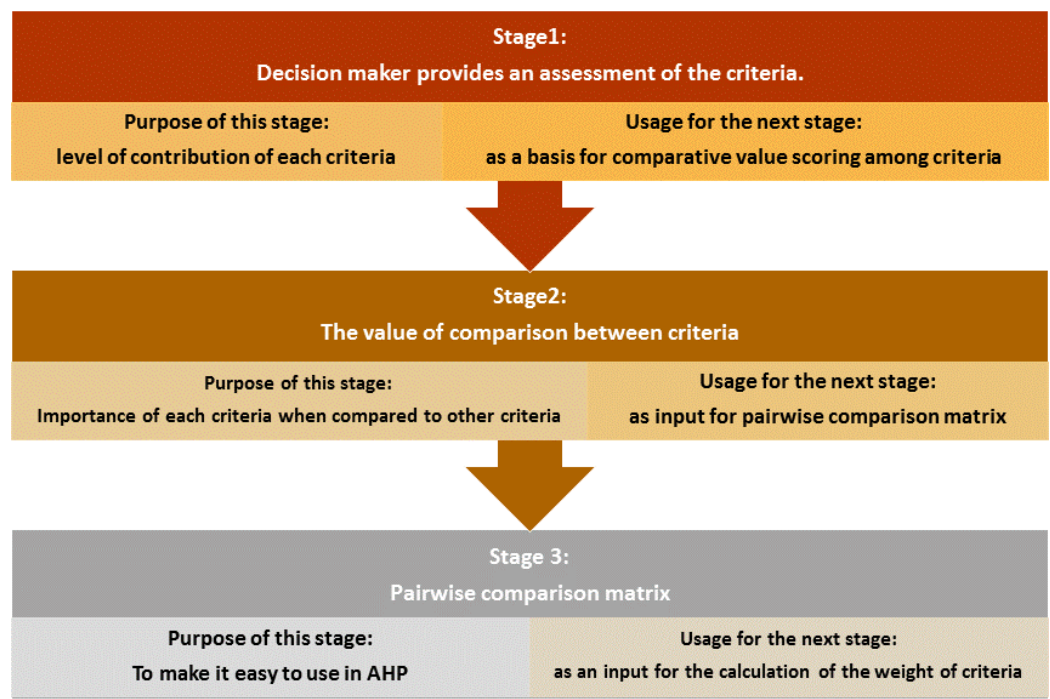

Figure 3 - Stages of the proposed method 
The difference between the proposed model and the original AHP lies in the process of generating the pairwise comparison matrix. In the original AHP, decision makers are required to compare one criterion against another. The results of each comparison are then included in the pairwise comparison matrix. This matrix is not necessarily consistent. In the proposed model, the decision maker assigns the level of importance (contribution value) of each criterion in supplier selection. Based on these values, a matrix pairwise comparison is generated.

\section{DISCUSSION OF RESULTS}

The performance of the proposed method. We assumed that there were nine criteria $\left(C_{1}, C_{2}, C_{3}, ., C_{9}\right)$, where the level of contribution was $x_{1}, x_{2}, x_{3}, ., x_{9}$ and $x_{i} \in\{1,2,3, ., 9$ Based on a comparison of the criteria, $C_{1}$ and $C_{2}$ were assigned a value of 1 and 2 , respectively. Criteria $C_{2}$ and $C_{1}$ were assigned a value of 2 . The values of the comparisons among the other criteria were obtained using the same calculation. Furthermore, we calculated the weight of each criterion and its consistency ratio. The results of the weight calculation and the consistency ratio, as well as the pairwise comparison matrix, are presented in Table 3.

Table 3 - Performance of the proposed method using successive levels

\begin{tabular}{llllllllll} 
Criteria & $C_{1}$ & $C_{2}$ & $C_{3}$ & $C_{4}$ & $C_{5}$ & $C_{6}$ & $C_{7}$ & $C_{8}$ & $C_{9}$ \\
\hline$C_{1}$ & 1.00 & 0.50 & 0.33 & 0.25 & 0.20 & 0.17 & 0.14 & 0.13 & 0.11 \\
$C_{2}$ & 2.00 & 1.00 & 0.67 & 0.50 & 0.40 & 0.33 & 0.29 & 0.25 & 0.22 \\
$C_{3}$ & 3.00 & 1.50 & 1.00 & 0.75 & 0.60 & 0.50 & 0.43 & 0.38 & 0.33 \\
$C_{4}$ & 4.00 & 2.00 & 1.33 & 1.00 & 0.80 & 0.67 & 0.57 & 0.50 & 0.44 \\
$C_{5}$ & 5.00 & 2.50 & 1.67 & 1.25 & 1.00 & 0.83 & 0.71 & 0.63 & 0.56 \\
$C_{6}$ & 6.00 & 3.00 & 2.00 & 1.50 & 1.20 & 1.00 & 0.86 & 0.75 & 0.67 \\
$C_{7}$ & 7.00 & 3.50 & 2.33 & 1.75 & 1.40 & 1.17 & 1.00 & 0.88 & 0.78 \\
$C_{8}$ & 8.00 & 4.00 & 2.67 & 2.00 & 1.60 & 1.33 & 1.14 & 1.00 & 0.89 \\
$C_{9}$ & 9.00 & 3.50 & 2.33 & 1.75 & 1.80 & 1.50 & 1.29 & 1.13 & 1.00 \\
\hline Contr. level & 1 & 2 & 3 & 4 & 5 & 6 & 7 & 8 & 9 \\
Weight & 0.023 & 0.045 & 0.068 & 0.090 & 0.113 & 0.136 & 0.158 & 0.181 & 0.186 \\
\hline CR & 0.008 (consistent) & & & & & & & &
\end{tabular}

If $x_{1}<x_{2}<x_{3}<x_{4}<x_{5}<x_{6}<x_{7}<x_{8}<x_{9}$, then $x_{1}=1, x_{2}=2, x_{3}=3$,., and $x_{9}=9$. If criteria $C_{9}$ are compared with the other criterion, the consistency ratio will always resultin a value greater than 1 , as shown in Table 3 (row $C_{9}$ ). Thus, the pairwise comparison matrix of $C_{9}$ criteria with other criteria gives consistent results. As the decision maker assigned $C_{1}$ the highest value (i.e., weakly or slightly important), the paired comparison value of criteria $C_{1}$ versus that of other criteria will always be $<1$. Therefore, $C_{9}$ will have the greatest weight. Likewise, the reverse is true for criteria $C_{1}$. Thus, if criteria $C_{1}$ is compared with the other criteria, it will always result in a value less than 1 and never more than 1 , as shown in Table 3 in the second row (row $C_{1}$ ). Thus, the pairwise comparison matrix of criteria $C_{1}$ with other criteria gives consistent results. As the decision maker assigned $C_{1}$ the lowest value (i.e., lowest importance), the paired comparison value of criteria $C_{9}$ versus that of other criteria will always be $>1$. As a result, $C_{1}$ will have the lowest weight. In terms of the other criteria, their weights will be in accordance with the order of the contribution value. Thus, it is logical that the weight of each criterion is determined by its contribution to supplier selection. Therefore, if each criterion makes the same contribution to supplier selection, it will have the same weight. Although all the supplier selection criteria have same value, the weights of all the criteria have the same value, as depicted in Table 4.

The contribution level of a particular criterion can be further evaluated by assigning a value of 0 to 100 (integer number), where 0 indicates no contribution to supplier selection, and 100 indicates the highest contribution (importance) of a criterion to supplier selection. The advantage of using contribution levels between 0 and 100 is the broad scope it gives decision makers to input the value of contributions of various criteria to supplier selection. In addition, if we use only an integer value range between 1 and 9, and there are more than 
nine criteria, then some criteria will have the same contribution level. However, if we use an integer value range between 0 and 100, this will minimize the chances of multiple criteria being assigned the same contribution value (level of importance).

Table 4 - Performance of the proposed method using same contribution value

\begin{tabular}{llllllllll} 
Criteria & $C_{1}$ & $C_{2}$ & $C_{3}$ & $C_{4}$ & $C_{5}$ & $C_{6}$ & $C_{7}$ & $C_{8}$ & $C_{9}$ \\
& 1 & 1 & 1 & 1 & 1 & 1 & 1 & 1 & 1 \\
& 2 & 2 & 2 & 2 & 2 & 2 & 2 & 2 & 2 \\
Contribution level & 3 & 3 & 3 & 3 & 3 & 3 & 3 & 3 & 3 \\
& 4 & 4 & 4 & 4 & 4 & 4 & 4 & 4 & 4 \\
& 5 & 5 & 5 & 5 & 5 & 5 & 5 & 5 & 5 \\
& 6 & 6 & 6 & 6 & 6 & 6 & 6 & 6 & 6 \\
Weight & 7 & 7 & 7 & 7 & 7 & 7 & 7 & 7 & 7 \\
\hline CR & 8 & 8 & 8 & 8 & 8 & 8 & 8 & 8 & 8 \\
& 9 & 9 & 9 & 9 & 9 & 9 & 9 & 9 & 9 \\
& 0.111 & 0.111 & 0.111 & 0.111 & 0.111 & 0.111 & 0.111 & 0.111 & 0.111 \\
\hline
\end{tabular}

Testing the proposed method using data from the literature. The proposed method was tested using previous data in which there were nine selection criteria [23, 24]. The pairwise comparison matrix in one study was inconsistent [23], whereas that in the other was consistent [24]. Tables 5 and 6 show the results of assessing the different contribution levels of decision makers for different criteria. As apparent in these tables, the proposed method yielded a consistent pairwise comparison matrix in the presence of more than nine criteria. Thus, the resulting supplier selection criteria will always be valid, regardless of the number of criteria. The proposed method was also capable of making inconsistent pairwise comparison matrices consistent and providing a definitive solution to supplier selection.

Table 5 - Example 1

\begin{tabular}{|c|c|c|c|c|c|}
\hline $\mathrm{n} / \mathrm{n}$ & {$[23]$} & \multicolumn{4}{|c|}{ Proposed method } \\
\hline Criteria & Weight & Contribution level (1-9) & Weight & Contribution level (0-100) & Weight \\
\hline$C_{1}$ & 0.291 & 9 & 0.181 & 60 & 0.327 \\
\hline$C_{2}$ & 0.229 & 8 & 0.161 & 25 & 0.136 \\
\hline$C_{3}$ & 0.114 & 7 & 0.141 & 22 & 0.120 \\
\hline$C_{4}$ & 0.114 & 7 & 0.141 & 20 & 0.109 \\
\hline$C_{5}$ & 0.036 & 3 & 0.060 & 12 & 0.065 \\
\hline$C_{6}$ & 0.037 & 3 & 0.060 & 8 & 0.044 \\
\hline$C_{7}$ & 0.036 & 3 & 0.060 & 7 & 0.038 \\
\hline$C_{8}$ & 0.068 & 5 & 0.100 & 15 & 0.082 \\
\hline$C_{9}$ & 0.052 & 4 & 0.076 & 10 & 0.052 \\
\hline$C_{10}$ & 0.023 & 1 & 0.020 & 5 & 0.027 \\
\hline$C_{1}$ & 0.184 (inconsistent) & 0.022 (consistent) & 0.003 (consistent) \\
\hline
\end{tabular}

Table 6 - Example 2

\begin{tabular}{|c|c|c|c|c|c|}
\hline & {$[24]$} & \multicolumn{4}{|c|}{ Proposed method } \\
\hline Criteria & Weight & Contribution level (1-9) & Weight & Contribution level (0-100) & Weight \\
\hline$C_{1}$ & 0.165 & 9 & 0.176 & 60 & 0.191 \\
\hline$C_{2}$ & 0.135 & 8 & 0.156 & 45 & 0.144 \\
\hline$C_{3}$ & 0.111 & 6 & 0.117 & 32 & 0.102 \\
\hline$C_{4}$ & 0.092 & 4 & 0.078 & 28 & 0.089 \\
\hline$C_{5}$ & 0.080 & 4 & 0.078 & 25 & 0.080 \\
\hline$C_{6}$ & 0.078 & 4 & 0.078 & 24 & 0.077 \\
\hline$C_{7}$ & 0.052 & 2 & 0.039 & 15 & 0.048 \\
\hline$C_{8}$ & 0.059 & 2 & 0.039 & 18 & 0.057 \\
\hline$C_{9}$ & 0.076 & 4 & 0.063 & 23 & 0.065 \\
\hline$C_{10}$ & 0.104 & 6 & 0.117 & 30 & 0.096 \\
\hline$C_{11}$ & 0.048 & 3 & 0.059 & 16 & 0.051 \\
\hline$C_{R}$ & 0.008 (consistent) & 0.012 (consistent) & 0.003 (consistent) \\
\hline
\end{tabular}


Comparison of the proposed method with that of Li et al. [19]. We compared the performance of the proposed method with that of Li et al. [19] using data from previous studies [23, [24]. In the pairwise comparison matrix of Hruska et al. [23], the method by Li et al. [19] does not accommodate numbers other than 1, 3, 5, 7, and 9 . Thus, number 8 is placed between numbers 7 and 9 , number 6 is placed between numbers 5 and 7 , and number 4 is placed between numbers 3 and 5 . Figure 4 show the results of the pairwise comparison conversion using the method of Hruska et al. [23] and that of Li et al. [9]. As shown in Figure 4, the pairwise comparison matrix based on the method of Li et al. [19] is inconsistent. Although the method used by Li et al. [19] can minimize inconsistencies, when there are more than seven criteria. This is one of the weaknesses of the method [19].

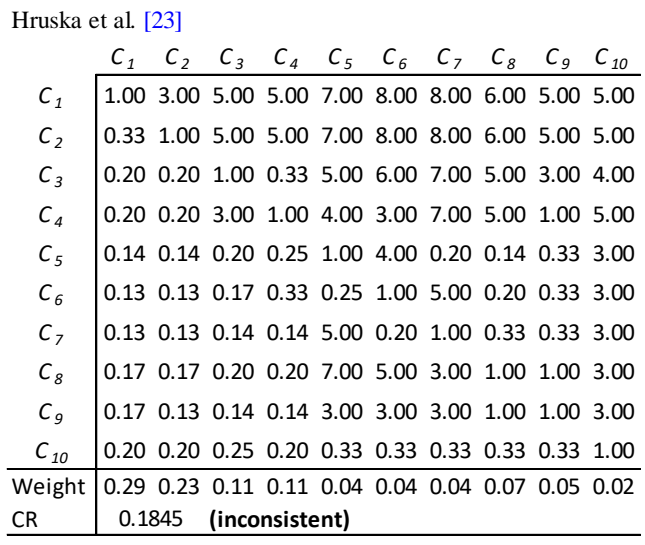

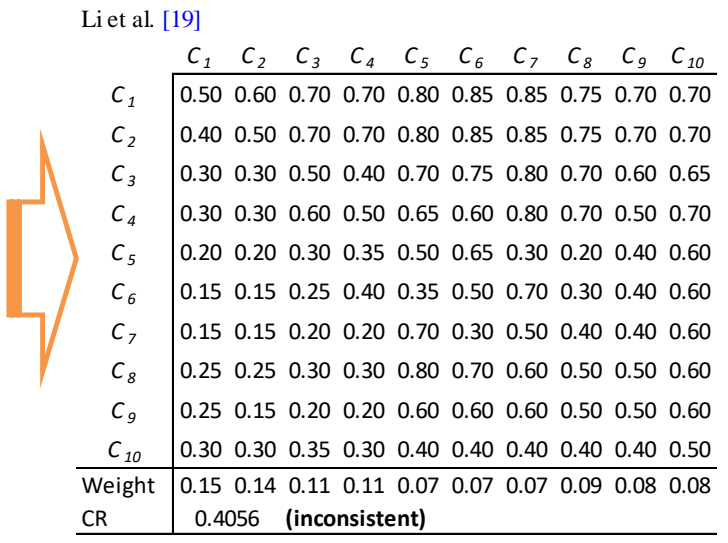

Figure 4 - Li et al. [19] for example 1

Example 2 provides additional evidence illustrating the disadvantages of the method of Li et al. [19]. Thus, the matrix data of by Polat et al. [24] must be rounded first, and then the matrix must be converted using the Li et al.'s method [19]. Figure 5 show the results of the pairwise comparison conversion using the method of Polat et al. [24] and that of Li et al. [9]. As can be seen in this figure, in a matrix that contains more than seven criteria, Li et al.'s method [19] produces an inconsistent solution. Table 7 provides a comparison of the results obtained using the method of Li et al. [19] with those obtained using the proposed method. Based on this table, it can be seen that the proposed method is better than that of $\mathrm{Li}$ et al. [19] because it always produces a consistent value. The proposed method is capable of giving a $\mathrm{Cl}$ value close to zero and a value of zero if the matrix is perfectly consistent [25].

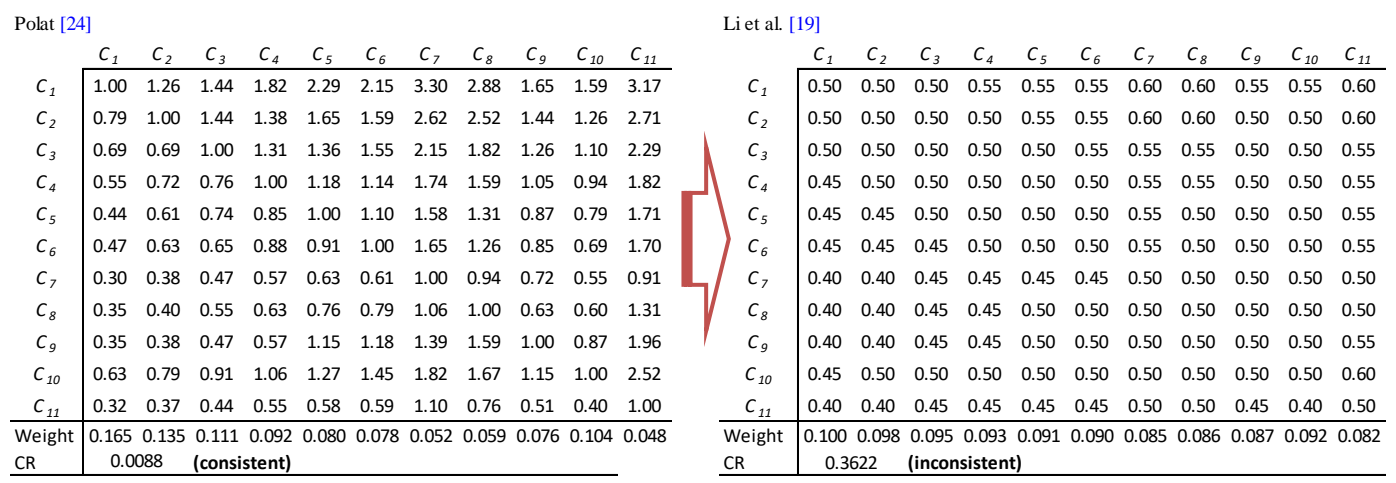

Figure 5 - Li et al. [19] for example 2

Comparison of the proposed method with that of Chandavarkar and Guddeti [18]. The performance of the proposed method was compared with that of Chandavarkar and Guddeti [18]. Chandavarkar and Guddeti [18] to construct a pairwise comparison matrix. In the pairwise comparison matrices of Hruška et al. [23] and Polat et al. [24], $L_{p}=L_{q}$. In equation (1), the value assigned to $a_{i j}$ is infinity. Thus, in the method used by Chandavarkar 
and Guddeti [18], the $a_{i j}$ value (infinity) is replaced by zero. This is one of the weaknesses of their method [18]. A comparison of the results obtained using their method [18] and those generated using the proposed method is presented in Tables 8 and 9. Based on these tables, it can be seen that the proposed method is better than that of Chandavarkar and Guddeti [18] because it always produces a consistent value. The proposed method is capable of giving a $\mathrm{Cl}$ value close to zero and a $\mathrm{Cl}$ value of zero if the matrix is perfectly consistent [25].

Table 7 - Summary of the results obtained using Li et al. [19] and those obtained using the proposed method

\begin{tabular}{ccccc}
\multirow{2}{*}{ Matrix data } & Size & \multicolumn{3}{c}{ Consistency ratio (CR) } \\
\cline { 3 - 5 } & & Original AHP & Li et al. [19] & Proposed method \\
\hline \hline Hruska et al. [23] & $10 \times 10$ & $\begin{array}{c}0.1845 \\
\text { (inconsistent) }\end{array}$ & $\begin{array}{c}0.4056 \\
\text { (inconsistent) }\end{array}$ & $\begin{array}{c}0.022 \\
\text { (consistent) }\end{array}$ \\
Polat [24] & $11 \times 11$ & $\begin{array}{c}0.0088 \\
\text { (consistent) }\end{array}$ & $\begin{array}{c}0.3622 \\
\text { (inconsistent) }\end{array}$ & $\begin{array}{c}0.012 \\
\text { (consistent) }\end{array}$ \\
\hline
\end{tabular}

Table 8 - Summary of the results obtained using the method Chandavarkar and Guddeti [18] and those obtained using the proposed method for example 1

\begin{tabular}{|c|c|c|c|c|}
\hline $\mathrm{n} / \mathrm{n}$ & {$[23]$} & Chandavarkar and Guddeti method [18] & \multicolumn{2}{|c|}{ Proposed method } \\
\hline Criteria & Weight & Weight & Contribution level (1-9) & Weight \\
\hline$C_{1}$ & 0.291 & 0.309 & 9 & 0.181 \\
\hline$C_{2}$ & 0.229 & 0.223 & 8 & 0.161 \\
\hline$C_{3}$ & 0.114 & 0.158 & 7 & 0.141 \\
\hline$C_{4}$ & 0.114 & 0.158 & 7 & 0.141 \\
\hline$C_{5}$ & 0.036 & 0.023 & 3 & 0.060 \\
\hline$C_{6}$ & 0.037 & 0.023 & 3 & 0.060 \\
\hline$C_{7}$ & 0.036 & 0.023 & 3 & 0.060 \\
\hline$C_{8}$ & 0.068 & 0.034 & 5 & 0.100 \\
\hline$C_{9}$ & 0.052 & 0.031 & 4 & 0.076 \\
\hline$C_{10}$ & 0.023 & 0.018 & 1 & 0.020 \\
\hline$C_{1}$ & 0.184 (inconsistent) & 0.066 (consistent) & 0.022 (consistent) \\
\hline
\end{tabular}

Table 9 - Summary of the results obtained using the Chandavarkar and Guddeti method [18] and those of the proposed method for example 2

\begin{tabular}{|c|c|c|c|c|}
\hline & {$[24]$} & Chandavarkar and Guddeti method [18] & \multicolumn{2}{|c|}{ Proposed method } \\
\hline Criteria & Weight & Weight & Contribution level (1-9) & Weight \\
\hline$C_{1}$ & 0.165 & 0.382 & 9 & 0.181 \\
\hline$C_{2}$ & 0.135 & 0.289 & 7 & 0.161 \\
\hline$C_{3}$ & 0.111 & 0.151 & 7 & 0.141 \\
\hline$C_{4}$ & 0.092 & 0.039 & 3 & 0.141 \\
\hline$C_{5}$ & 0.080 & 0.039 & 3 & 0.060 \\
\hline$C_{6}$ & 0.078 & 0.039 & 3 & 0.060 \\
\hline$C_{7}$ & 0.052 & 0.007 & 5 & 0.060 \\
\hline$C_{8}$ & 0.059 & 0.007 & 4 & 0.100 \\
\hline$C_{9}$ & 0.076 & 0.005 & 1 & 0.076 \\
\hline$C_{10}$ & 0.104 & 0.013 & & 0.020 \\
\hline$C_{11}$ & 0.048 & 0.028 & 0.022 (consistent) & \\
\hline$C_{2}$ & 0.008 (consistent) & 0.299 (inconsistent) & & \\
\hline
\end{tabular}

Test of the effect of criteria weight on supplier selection using the proposed method. We examined the effect of criteria weight on supplier selection using the proposed method as compared with that using the original AHP. The data used in the test are shown in Tables 10 and 11. These data are performance data from each supplier for each criterion. As shown in the tables, there are six suppliers (SC1, SC2, SC3, SC4, SC5, and SC6). 
Table 10 - Supplier data for example 1

\begin{tabular}{ccccccccccc} 
Supplier & $C_{1}$ & $C_{2}$ & $C_{3}$ & $C_{4}$ & $C_{5}$ & $C_{6}$ & $C_{7}$ & $C_{8}$ & $C_{9}$ & $C_{10}$ \\
\hline SC1 & 8 & 5 & 3 & 1 & 8 & 7 & 8 & 3 & 5 & 3 \\
SC2 & 10 & 6 & 5 & 2 & 7 & 10 & 5 & 1 & 8 & 1 \\
SC3 & 10 & 6 & 3 & 3 & 5 & 8 & 6 & 4 & 5 & 5 \\
SC4 & 9 & 7 & 4 & 2 & 4 & 11 & 2 & 3 & 7 & 0 \\
SC5 & 12 & 8 & 4 & 2 & 6 & 9 & 4 & 0 & 8 & 2 \\
SC6 & 10 & 6 & 8 & 4 & 5 & 6 & 3 & 2 & 7 & 1 \\
\hline
\end{tabular}

Table 11 - Supplier data for example 2

\begin{tabular}{cccccccccccc} 
Supplier & $C_{1}$ & $C_{2}$ & $C_{3}$ & $C_{4}$ & $C_{5}$ & $C_{6}$ & $C_{7}$ & $C_{8}$ & $C_{9}$ & $C_{10}$ & $C_{11}$ \\
\hline SC1 & 8 & 5 & 3 & 1 & 8 & 7 & 8 & 3 & 5 & 3 & 8 \\
SC2 & 10 & 6 & 5 & 2 & 7 & 10 & 5 & 1 & 8 & 1 & 6 \\
SC3 & 10 & 6 & 3 & 3 & 5 & 8 & 6 & 4 & 5 & 5 & 10 \\
SC4 & 9 & 7 & 4 & 2 & 4 & 11 & 2 & 3 & 7 & 0 & 4 \\
SC5 & 12 & 8 & 4 & 2 & 6 & 9 & 4 & 0 & 8 & 2 & 5 \\
SC5 & 10 & 6 & 8 & 4 & 5 & 6 & 3 & 2 & 7 & 1 & 9 \\
\hline
\end{tabular}

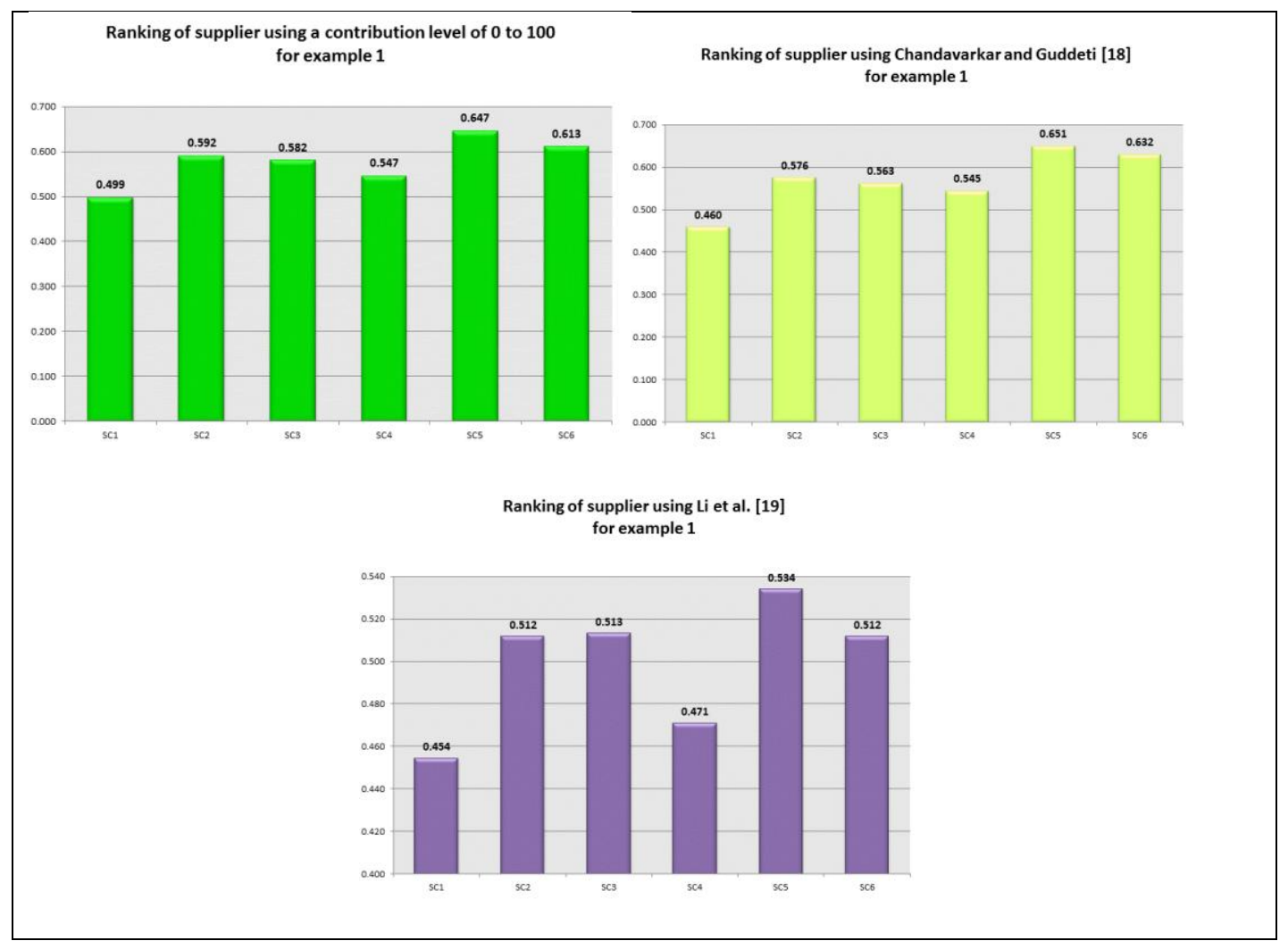

Figure 6 - Supplier selection solution (example 1)

Figure 6 is the result of the proposed method using supplier data in Table 10. Figures 7 is the result of the proposed method using supplier data in Table 11. The results of the sequence of suppliers are the same in Figure 6. Test supplier is SC 5, and the worst supplier is SC 1. It was inconsistent in the pairwise comparison matrices of Hruska et al. [23] but consistent when using the proposed method Thus, the results obtained by Hruska et al. [23] and those obtained using the method of Li et al. [19] are invalid, although they yield the same solution as that obtained using the proposed method.

Using the pairwise comparison matrix of by Polat [24] gives the solution shown in Figure 7. Figure 7 shows that the solution of the proposed method is the same as that generated using the original AHP. The results obtained using the method of Chandavarkar and Guddeti [18] are invalid, although the method yields the same solution as those generated using the proposed method. Proposed method produce the same solution as that 
obtained using a consistent pairwise comparison matrix. An inconsistent matrix results in a different supplier selection solution.

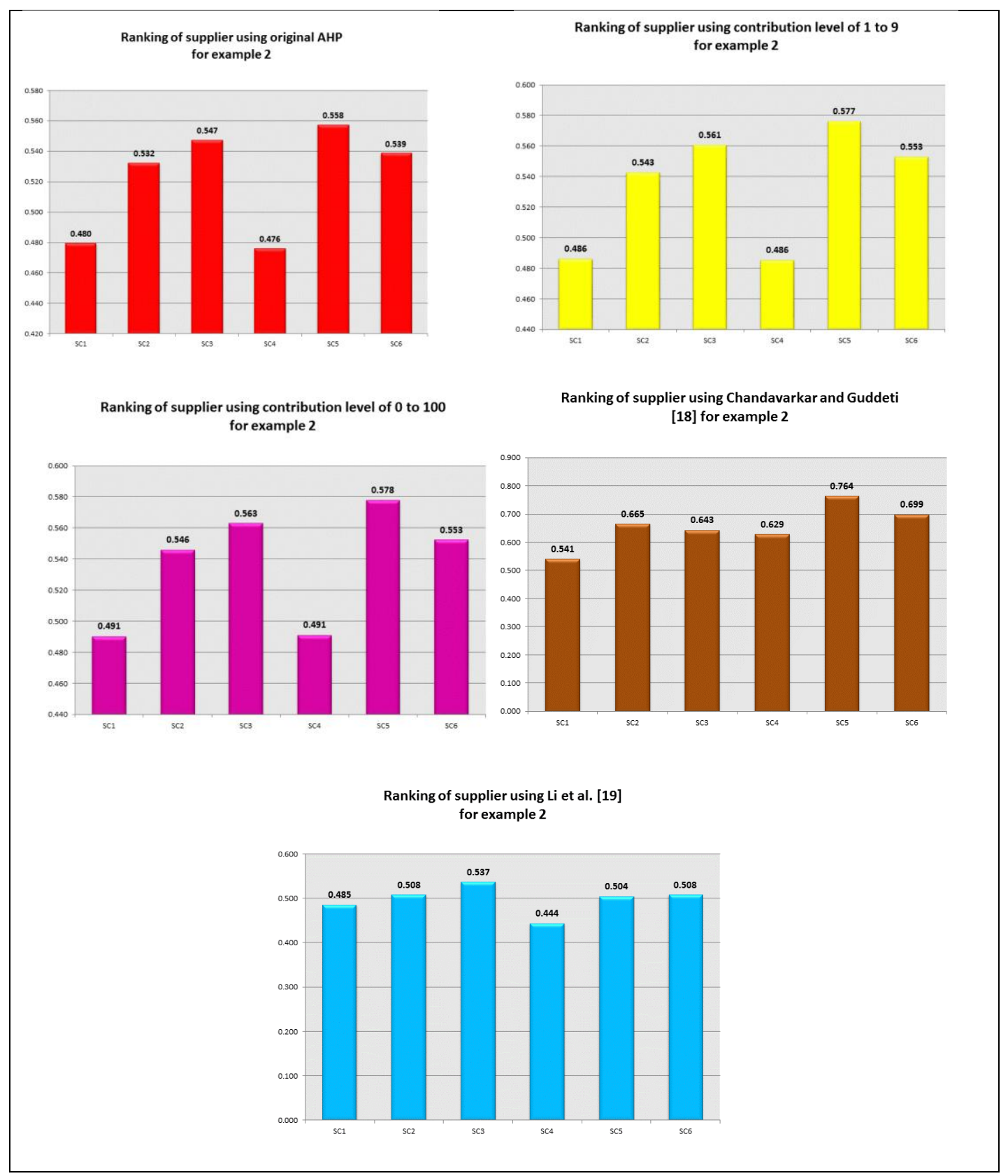

Figure 7 - Supplier selection solution (example 2)

\section{CONCLUSION}

The solution obtained using the proposed method is better than that achieved using the method of Li et al. [19] and that of Chandavarkar and Guddeti [18], as the proposed method is capable of generating a valid solution, regardless of the number of criteria and without having to revise the pairwise comparison matrix. The proposed method is also easier to use because decision makers have only to assign a contribution level to each criterion rather than drawing comparisons between criteria. Furthermore, the proposed method is simpler than the original AHP, as it does not require a consistency test. In addition, using the proposed method, the pairwise comparison matrix does not have to be complete.

This research was financially supported by the PDD Program of the Ristekdikti Republic of Indonesia. 
Limitations of the study. The proposed method has not been tested using real data.

Conflict of interest. The authors declare that there are no conflicts of interest.

\section{ACKNOWLEDGEMENTS}

The authors thank the Ministry of Research, Technology and Higher Education of the Republic of Indonesia for its financial support.

\section{REFERENCES}

1. Rezaei, J., Nispeling, T., Sarkis, J., and Tavasszy, L., "A supplier selection life cycle approach integrating traditional and environmental criteria using the best worst method," Journal of Cleaner Production, Vol. 135, pp. 577-588, 2016.

2. Chai, J., Liu, J. N. K., and Ngai, E. W. T., "Application of decision-making techniques in supplier selection: A systematic review of literature," Expert Systems with Applications, Vol. 40, no. 10, pp. 3872-3885, 2013.

3. Banaeian, N., Mobli, H., Fahimnia, B., Nielsen, I. E., and Omid, M., "Green supplier selection using fuzzy group decision making methods: A case study from the agri-food industry," Computers \& Operations research, Vol. 89, no. 1, pp. 337-347, 2017.

4. Govindan, K., Rajendran, S., Sarkis, J., and Murugesan, P., "Multi criteria decision making approaches for green supplier evaluation and selection: a literature review," Journal of Cleaner Production, Vol. 98, pp. 66 - 83, 2015.

5. Zimmer, K., Fröhling, M., and Schultmann, F., "Sustainable supplier management - a review of models supporting sustainable supplier selection, monitoring and development," International Journal of Production Research, Vol. 54, no. 5, pp. 1412-1442, 2017.

6. Rosyidi, C. N., Murtisari, R., and Jauhari, W. A., "A concurrent optimization model for suppliers selection, tolerance and component allocation with fuzzy quality loss," Cogent Engineering, Vol. 3, no. 1, pp. 1-10, 2016.

7. Saaty, T. L., "Decision-making with the AHP: Why is the principal eigenvector necessary," European Journal of Operational Research, Vol. 145, no. 1, pp. 85-91, 2003.

8. Saaty, T. L., "How to make a decision: The Analytic Hierarchy Process," European Journal of Operational Research, Vol. 48, no. 1, pp. 9-26, 1990.

9. Darabi, S. and Heydari, J., "An interval-valued hesitant fuzzy ranking method based on group decision analysis for green supplier selection," IFAC-paper On Line, Vol. 49, no. 2, pp. 12-17, 2016.

10. Tavana, M., Fallahpour, A., Di-Caprio, D. and Santos-Arteaga, F. J., "A hybrid intelligent fuzzy predictive model with simulation for supplier evaluation and selection," Expert Systems With Applications, Vol. 61, pp. 129-144, 2016.

11. Hamdan, S. and Cheaitou, A., "Supplier selection and order allocation with green criteria: An MCDM and multi-objective optimization approach", Computers and Operation Research, Vol. 81, pp. $282-304,2017$.

12. Saaty, T. L. and Kearns, K. P., "Analytical planning: The organization systems," Oxford: Pergamon press, pp. 34-36, 1985.

13. Saaty, T. L. and Ozdemir, M. S., "Why the magic number seven plus or minus two," Mathematical and Computer Modelling, Vol. 38, no. 3-4, pp. 233-44, 2003.

14. Luzon, B. and El-Sayegh, S. M., "Evaluating supplier selection criteria for oil and gas projects in the UAE using AHP and Delphi," International Journal of Construction Management, Vol. 140, no. 3, pp. 1686-1698, 2016.

15. Dweiri, F., Kumar, S., Khan, S. A., and Jain, V., "Designing an integrated AHP based decision support system for supplier selection in automotive industry," Expert Systems With Applications, Vol. 62, pp. 273-283, 2016.

16. Pandey, P., Shah, B. J., and Gajjar, H., "A fuzzy goal programming approach for selecting sustainable suppliers," Benchmarking: An International Journal, Vol. 24, no. 5, 2017.

17. Luthra, S., Govindan, K., Kannan, D., Mangla, S. K., and Garg, C. P., "An integrated 
framework for sustainable supplier selection and evaluation in supply chains," Journal of Cleaner Production, Vol. 140, no. 3, pp. 1686-1698, 2017.

18. Chandavarkar, B. R. and Guddeti, R. M. R., "Simplified and Improved Analytical Hierarchy Process Aid for Selecting Candidate Network in an Overlay Heterogeneous Networks," Wireless Personal Communications, Vol. 83, no. 4, pp. 2593-2606, 2015.

19. Li, Z., Li, J., Liang, D., and Lee, T., "Building multilevel governance and partnerships: an evaluation approach," Journal of Entrepreneurship in Emerging Economies, Vol. 8, no. 2, pp. $263-278,2016$.

20. Galankashi, M. R., Helmi, S. A., and Hashemzahi, P., "Supplier selection in automobile industry: A mixed balanced scorecard-fuzzy AHP approach," Alexandria Engineering Journal, Vol. 55, pp. 93 - 100, 2016.

21. Saaty, T. L., "Rank from comparisons and from ratings in the analytic hierarchy/network processes," European Journal of Operational Research, Vol. 168, no. 2, pp. 557-570, 2006.

22. Lin, Y. and Xiaohong, D., "The Computation and Application of random consistency index," 2nd International Conference on Information Science and Engineering (ICISE) IEEE, 4-6 Dec 2010, pp. 693 - 695, 2010.

23. Hruška, R., Průša, P. and Babić, D., "The use of AHP method for selection of supplier," Transport, Vol. 29, no. 2, pp. 195 - 203, 2014.

24. Polat, G., "Subcontractor selection using the integration of the AHP and PROMETHEE methods," Journal of Civil Engineering and Management, Vol. 22, no. 8, pp. 1042-1054, 2015.

25. Franek, J. And Kresta, A., "Judgment scales and consistency measure in AHP," Procedia Economics and Finance, Vol. 12, pp. 164 - 173, 2014.

\section{APPENDIX}

\begin{tabular}{|c|c|c|c|c|}
\hline $\begin{array}{c}\text { Criteria } \mathrm{C} 1 \text { is compared with } \\
\text { criteria } \mathrm{C} 2\end{array}$ & $\begin{array}{c}\text { Criteria C2 is compared with } \\
\text { criteria C3 }\end{array}$ & $\begin{array}{c}\text { Criteria C1 is compared with } \\
\text { criteria C3 }\end{array}$ & $\begin{array}{l}\text { Consistency } \\
\text { ratio }(\mathrm{CR})\end{array}$ & Conclusion \\
\hline \multirow[t]{8}{*}{ 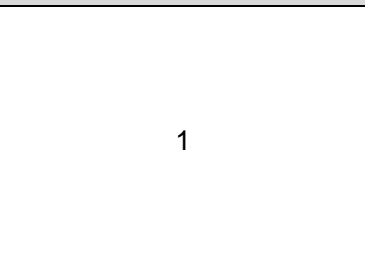 } & 2 & $1 / 2$ & 0.209 & Inconsistent \\
\hline & 3 & $1 / 2$ & 0.356 & Inconsistent \\
\hline & 4 & $1 / 2$ & 0.490 & Inconsistent \\
\hline & 5 & $1 / 2$ & 0.613 & Inconsistent \\
\hline & 6 & $1 / 2$ & 0.730 & Inconsistent \\
\hline & 7 & $1 / 2$ & 0.843 & Inconsistent \\
\hline & 8 & $1 / 2$ & 0.951 & Inconsistent \\
\hline & 9 & $1 / 2$ & 1.057 & Inconsistent \\
\hline \multirow{9}{*}{2} & 1 & $1 / 2$ & 0.209 & Inconsistent \\
\hline & 2 & $1 / 2$ & 0.481 & Inconsistent \\
\hline & 3 & $1 / 2$ & 0.700 & Inconsistent \\
\hline & 4 & $1 / 2$ & 0.890 & Inconsistent \\
\hline & 5 & $1 / 2$ & 1.063 & Inconsistent \\
\hline & 6 & $1 / 2$ & 1.224 & Inconsistent \\
\hline & 7 & $1 / 2$ & 1.378 & Inconsistent \\
\hline & 8 & $1 / 2$ & 1.526 & Inconsistent \\
\hline & 9 & $1 / 2$ & 1.670 & Inconsistent \\
\hline \multirow{9}{*}{3} & 1 & $1 / 2$ & 0.356 & Inconsistent \\
\hline & 2 & $1 / 2$ & 0.700 & Inconsistent \\
\hline & 3 & $1 / 2$ & 0.967 & Inconsistent \\
\hline & 4 & $1 / 2$ & 1.193 & Inconsistent \\
\hline & 5 & $1 / 2$ & 1.397 & Inconsistent \\
\hline & 6 & $1 / 2$ & 1.586 & Inconsistent \\
\hline & 7 & $1 / 2$ & 1.764 & Inconsistent \\
\hline & 8 & $1 / 2$ & 1.936 & Inconsistent \\
\hline & 9 & $1 / 2$ & 2.103 & Inconsistent \\
\hline \multirow{9}{*}{4} & 1 & $1 / 2$ & 0.906 & Inconsistent \\
\hline & 2 & $1 / 2$ & 1.450 & Inconsistent \\
\hline & 3 & $1 / 2$ & 1.841 & Inconsistent \\
\hline & 4 & $1 / 2$ & 2.163 & Inconsistent \\
\hline & 5 & $1 / 2$ & 2.448 & Inconsistent \\
\hline & 6 & $1 / 2$ & 2.711 & Inconsistent \\
\hline & 7 & $1 / 2$ & 2.958 & Inconsistent \\
\hline & 8 & $1 / 2$ & 3.194 & Inconsistent \\
\hline & 9 & $1 / 2$ & 3.424 & Inconsistent \\
\hline
\end{tabular}


RJOAS, 3(87), March 2019

\begin{tabular}{|c|c|c|c|c|}
\hline \multirow{9}{*}{5} & 1 & $1 / 2$ & 0.608 & Inconsistent \\
\hline & 2 & $1 / 2$ & 1.063 & Inconsistent \\
\hline & 3 & $1 / 2$ & 1.400 & Inconsistent \\
\hline & 4 & $1 / 2$ & 1.680 & Inconsistent \\
\hline & 5 & $1 / 2$ & 1.926 & Inconsistent \\
\hline & 6 & $1 / 2$ & 2.152 & Inconsistent \\
\hline & 7 & $1 / 2$ & 2.364 & Inconsistent \\
\hline & 8 & $1 / 2$ & 2.567 & Inconsistent \\
\hline & 9 & $1 / 2$ & 2.762 & Inconsistent \\
\hline \multirow{9}{*}{6} & 1 & $1 / 2$ & 0.721 & Inconsistent \\
\hline & 2 & $1 / 2$ & 1.224 & Inconsistent \\
\hline & 3 & $1 / 2$ & 1.592 & Inconsistent \\
\hline & 4 & $1 / 2$ & 1.893 & Inconsistent \\
\hline & 5 & $1 / 2$ & 2.157 & Inconsistent \\
\hline & 6 & $1 / 2$ & 2.397 & Inconsistent \\
\hline & 7 & $1 / 2$ & 2.622 & Inconsistent \\
\hline & 8 & $1 / 2$ & 2.836 & Inconsistent \\
\hline & 9 & $1 / 2$ & 3.042 & Inconsistent \\
\hline \multirow{9}{*}{7} & 1 & $1 / 2$ & 0.829 & Inconsistent \\
\hline & 2 & $1 / 2$ & 1.378 & Inconsistent \\
\hline & 3 & $1 / 2$ & 1.774 & Inconsistent \\
\hline & 4 & $1 / 2$ & 2.096 & Inconsistent \\
\hline & 5 & $1 / 2$ & 2.375 & Inconsistent \\
\hline & 6 & $1 / 2$ & 2.629 & Inconsistent \\
\hline & 7 & $1 / 2$ & 2.865 & Inconsistent \\
\hline & 8 & $1 / 2$ & 3.089 & Inconsistent \\
\hline & 9 & $1 / 2$ & 3.304 & Inconsistent \\
\hline \multirow{9}{*}{8} & 1 & $1 / 2$ & 0.933 & Inconsistent \\
\hline & 2 & $1 / 2$ & 1.526 & Inconsistent \\
\hline & 3 & $1 / 2$ & 1.949 & Inconsistent \\
\hline & 4 & $1 / 2$ & 2.291 & Inconsistent \\
\hline & 5 & $1 / 2$ & 2.585 & Inconsistent \\
\hline & 6 & $1 / 2$ & 2.851 & Inconsistent \\
\hline & 7 & $1 / 2$ & 3.097 & Inconsistent \\
\hline & 8 & $1 / 2$ & 3.330 & Inconsistent \\
\hline & 9 & $1 / 2$ & 3.553 & Inconsistent \\
\hline \multirow{9}{*}{9} & 1 & $1 / 2$ & 1.033 & Inconsistent \\
\hline & 2 & $1 / 2$ & 1.670 & Inconsistent \\
\hline & 3 & $1 / 2$ & 2.120 & Inconsistent \\
\hline & 4 & $1 / 2$ & 2.480 & Inconsistent \\
\hline & 5 & $1 / 2$ & 2.789 & Inconsistent \\
\hline & 6 & $1 / 2$ & 3.066 & Inconsistent \\
\hline & 7 & $1 / 2$ & 3.322 & Inconsistent \\
\hline & 8 & $1 / 2$ & 3.563 & Inconsistent \\
\hline & 9 & $1 / 2$ & 3.793 & Inconsistent \\
\hline \multirow{9}{*}{1} & 1 & $1 / 3$ & 0.131 & Inconsistent \\
\hline & 2 & $1 / 3$ & 0.356 & Inconsistent \\
\hline & 3 & $1 / 3$ & 0.546 & Inconsistent \\
\hline & 4 & $1 / 3$ & 0.714 & Inconsistent \\
\hline & 5 & $1 / 3$ & 0.869 & Inconsistent \\
\hline & 6 & $1 / 3$ & 1.014 & Inconsistent \\
\hline & 7 & $1 / 3$ & 1.152 & Inconsistent \\
\hline & 8 & $1 / 3$ & 1.286 & Inconsistent \\
\hline & 9 & $1 / 3$ & 1.417 & Inconsistent \\
\hline \multirow{9}{*}{2} & 1 & $1 / 3$ & 0.356 & Inconsistent \\
\hline & 2 & $1 / 3$ & 0.700 & Inconsistent \\
\hline & 3 & $1 / 3$ & 0.967 & Inconsistent \\
\hline & 4 & $1 / 3$ & 1.195 & Inconsistent \\
\hline & 5 & $1 / 3$ & 1.400 & Inconsistent \\
\hline & 6 & $1 / 3$ & 1.592 & Inconsistent \\
\hline & 7 & $1 / 3$ & 1.774 & Inconsistent \\
\hline & 8 & $1 / 3$ & 1.949 & Inconsistent \\
\hline & 9 & $1 / 3$ & 2.120 & Inconsistent \\
\hline \multirow{9}{*}{3} & 1 & $1 / 3$ & 0.546 & Inconsistent \\
\hline & 2 & $1 / 3$ & 0.967 & Inconsistent \\
\hline & 3 & $1 / 3$ & 1.282 & Inconsistent \\
\hline & 4 & $1 / 3$ & 1.547 & Inconsistent \\
\hline & 5 & $1 / 3$ & 1.784 & Inconsistent \\
\hline & 6 & $1 / 3$ & 2.004 & Inconsistent \\
\hline & 7 & $1 / 3$ & 2.212 & Inconsistent \\
\hline & 8 & $1 / 3$ & 2.412 & Inconsistent \\
\hline & 9 & $1 / 3$ & 2.606 & Inconsistent \\
\hline
\end{tabular}




\begin{tabular}{|c|c|c|c|c|}
\hline \multirow{9}{*}{4} & 1 & $1 / 3$ & 0.711 & Inconsistent \\
\hline & 2 & $1 / 3$ & 1.193 & Inconsistent \\
\hline & 3 & $1 / 3$ & 1.547 & Inconsistent \\
\hline & 4 & $1 / 3$ & 1.841 & Inconsistent \\
\hline & 5 & $1 / 3$ & 2.102 & Inconsistent \\
\hline & 6 & $1 / 3$ & 2.342 & Inconsistent \\
\hline & 7 & $1 / 3$ & 2.568 & Inconsistent \\
\hline & 8 & $1 / 3$ & 2.786 & Inconsistent \\
\hline & 9 & $1 / 3$ & 2.996 & Inconsistent \\
\hline \multirow{9}{*}{5} & 1 & $1 / 3$ & 0.861 & Inconsistent \\
\hline & 2 & $1 / 3$ & 1.397 & Inconsistent \\
\hline & 3 & $1 / 3$ & 1.784 & Inconsistent \\
\hline & 4 & $1 / 3$ & 2.102 & Inconsistent \\
\hline & 5 & $1 / 3$ & 2.383 & Inconsistent \\
\hline & 6 & $1 / 3$ & 2.640 & Inconsistent \\
\hline & 7 & $1 / 3$ & 2.881 & Inconsistent \\
\hline & 8 & $1 / 3$ & 3.112 & Inconsistent \\
\hline & 9 & $1 / 3$ & 3.335 & Inconsistent \\
\hline \multirow{9}{*}{6} & 1 & $1 / 3$ & 0.999 & Inconsistent \\
\hline & 2 & $1 / 3$ & 1.586 & Inconsistent \\
\hline & 3 & $1 / 3$ & 2.004 & Inconsistent \\
\hline & 4 & $1 / 3$ & 2.344 & Inconsistent \\
\hline & 5 & $1 / 3$ & 2.642 & Inconsistent \\
\hline & 6 & $1 / 3$ & 2.913 & Inconsistent \\
\hline & 7 & $1 / 3$ & 3.167 & Inconsistent \\
\hline & 8 & $1 / 3$ & 3.409 & Inconsistent \\
\hline & 9 & $1 / 3$ & 3.643 & Inconsistent \\
\hline \multirow{9}{*}{7} & 1 & $1 / 3$ & 1.130 & Inconsistent \\
\hline & 2 & $1 / 3$ & 1.764 & Inconsistent \\
\hline & 3 & $1 / 3$ & 2.212 & Inconsistent \\
\hline & 4 & $1 / 3$ & 2.573 & Inconsistent \\
\hline & 5 & $1 / 3$ & 2.886 & Inconsistent \\
\hline & 6 & $1 / 3$ & 3.170 & Inconsistent \\
\hline & 7 & $1 / 3$ & 3.436 & Inconsistent \\
\hline & 8 & $1 / 3$ & 3.688 & Inconsistent \\
\hline & 9 & $1 / 3$ & 3.930 & Inconsistent \\
\hline \multirow{9}{*}{8} & 1 & $1 / 3$ & 1.254 & Inconsistent \\
\hline & 2 & $1 / 3$ & 1.936 & Inconsistent \\
\hline & 3 & $1 / 3$ & 2.412 & Inconsistent \\
\hline & 4 & $1 / 3$ & 2.792 & Inconsistent \\
\hline & 5 & $1 / 3$ & 3.120 & Inconsistent \\
\hline & 6 & $1 / 3$ & 3.417 & Inconsistent \\
\hline & 7 & $1 / 3$ & 3.692 & Inconsistent \\
\hline & 8 & $1 / 3$ & 3.953 & Inconsistent \\
\hline & 9 & $1 / 3$ & 4.203 & Inconsistent \\
\hline \multirow{9}{*}{9} & 1 & $1 / 3$ & 1.375 & Inconsistent \\
\hline & 2 & $1 / 3$ & 2.103 & Inconsistent \\
\hline & 3 & $1 / 3$ & 2.606 & Inconsistent \\
\hline & 4 & $1 / 3$ & 3.005 & Inconsistent \\
\hline & 5 & $1 / 3$ & 3.347 & Inconsistent \\
\hline & 6 & $1 / 3$ & 3.655 & Inconsistent \\
\hline & 7 & $1 / 3$ & 3.940 & Inconsistent \\
\hline & 8 & $1 / 3$ & 4.209 & Inconsistent \\
\hline & 9 & $1 / 3$ & 4.466 & Inconsistent \\
\hline \multirow{9}{*}{1} & 1 & $1 / 4$ & 0.211 & Inconsistent \\
\hline & 2 & $1 / 4$ & 0.487 & Inconsistent \\
\hline & 3 & $1 / 4$ & 0.711 & Inconsistent \\
\hline & 4 & $1 / 4$ & 0.906 & Inconsistent \\
\hline & 5 & $1 / 4$ & 1.084 & Inconsistent \\
\hline & 6 & $1 / 4$ & 1.250 & Inconsistent \\
\hline & 7 & $1 / 4$ & 1.408 & Inconsistent \\
\hline & 8 & $1 / 4$ & 1.561 & Inconsistent \\
\hline & 9 & $1 / 4$ & 1.709 & Inconsistent \\
\hline \multirow{9}{*}{2} & 1 & $1 / 4$ & 0.490 & Inconsistent \\
\hline & 2 & $1 / 4$ & 0.890 & Inconsistent \\
\hline & 3 & $1 / 4$ & 1.193 & Inconsistent \\
\hline & 4 & $1 / 4$ & 1.450 & Inconsistent \\
\hline & 5 & $1 / 4$ & 1.680 & Inconsistent \\
\hline & 6 & $1 / 4$ & 1.893 & Inconsistent \\
\hline & 7 & $1 / 4$ & 2.096 & Inconsistent \\
\hline & 8 & $1 / 4$ & 2.291 & Inconsistent \\
\hline & 9 & $1 / 4$ & 2.480 & Inconsistent \\
\hline
\end{tabular}


RJOAS, 3(87), March 2019

\begin{tabular}{|c|c|c|c|c|}
\hline \multirow{9}{*}{3} & 1 & $1 / 4$ & 0.714 & Inconsistent \\
\hline & 2 & $1 / 4$ & 1.195 & Inconsistent \\
\hline & 3 & $1 / 4$ & 1.547 & Inconsistent \\
\hline & 4 & $1 / 4$ & 1.841 & Inconsistent \\
\hline & 5 & $1 / 4$ & 2.102 & Inconsistent \\
\hline & 6 & $1 / 4$ & 2.344 & Inconsistent \\
\hline & 7 & $1 / 4$ & 2.573 & Inconsistent \\
\hline & 8 & $1 / 4$ & 2.792 & Inconsistent \\
\hline & 9 & $1 / 4$ & 3.005 & Inconsistent \\
\hline \multirow{9}{*}{4} & 1 & $1 / 4$ & 0.906 & Inconsistent \\
\hline & 2 & $1 / 4$ & 1.450 & Inconsistent \\
\hline & 3 & $1 / 4$ & 1.841 & Inconsistent \\
\hline & 4 & $1 / 4$ & 2.163 & Inconsistent \\
\hline & 5 & $1 / 4$ & 2.448 & Inconsistent \\
\hline & 6 & $1 / 4$ & 2.711 & Inconsistent \\
\hline & 7 & $1 / 4$ & 2.958 & Inconsistent \\
\hline & 8 & $1 / 4$ & 3.194 & Inconsistent \\
\hline & 9 & $1 / 4$ & 3.424 & Inconsistent \\
\hline \multirow{9}{*}{5} & 1 & $1 / 4$ & 1.078 & Inconsistent \\
\hline & 2 & $1 / 4$ & 1.677 & Inconsistent \\
\hline & 3 & $1 / 4$ & 2.102 & Inconsistent \\
\hline & 4 & $1 / 4$ & 2.448 & Inconsistent \\
\hline & 5 & $1 / 4$ & 2.753 & Inconsistent \\
\hline & 6 & $1 / 4$ & 3.032 & Inconsistent \\
\hline & 7 & $1 / 4$ & 3.294 & Inconsistent \\
\hline & 8 & $1 / 4$ & 3.544 & Inconsistent \\
\hline & 9 & $1 / 4$ & 3.786 & Inconsistent \\
\hline \multirow{9}{*}{6} & 1 & $1 / 4$ & 1.235 & Inconsistent \\
\hline & 2 & $1 / 4$ & 1.886 & Inconsistent \\
\hline & 3 & $1 / 4$ & 2.342 & Inconsistent \\
\hline & 4 & $1 / 4$ & 2.711 & Inconsistent \\
\hline & 5 & $1 / 4$ & 3.032 & Inconsistent \\
\hline & 6 & $1 / 4$ & 3.325 & Inconsistent \\
\hline & 7 & $1 / 4$ & 3.600 & Inconsistent \\
\hline & 8 & $1 / 4$ & 3.861 & Inconsistent \\
\hline & 9 & $1 / 4$ & 4.113 & Inconsistent \\
\hline \multirow{9}{*}{7} & 1 & $1 / 4$ & 1.383 & Inconsistent \\
\hline & 2 & $1 / 4$ & 2.083 & Inconsistent \\
\hline & 3 & $1 / 4$ & 2.568 & Inconsistent \\
\hline & 4 & $1 / 4$ & 2.958 & Inconsistent \\
\hline & 5 & $1 / 4$ & 3.295 & Inconsistent \\
\hline & 6 & $1 / 4$ & 3.601 & Inconsistent \\
\hline & 7 & $1 / 4$ & 3.886 & Inconsistent \\
\hline & 8 & $1 / 4$ & 4.158 & Inconsistent \\
\hline & 9 & $1 / 4$ & 4.418 & Inconsistent \\
\hline \multirow{9}{*}{8} & 1 & $1 / 4$ & 1.524 & Inconsistent \\
\hline & 2 & $1 / 4$ & 2.272 & Inconsistent \\
\hline & 3 & $1 / 4$ & 2.786 & Inconsistent \\
\hline & 4 & $1 / 4$ & 3.194 & Inconsistent \\
\hline & 5 & $1 / 4$ & 3.547 & Inconsistent \\
\hline & 6 & $1 / 4$ & 3.864 & Inconsistent \\
\hline & 7 & $1 / 4$ & 4.160 & Inconsistent \\
\hline & 8 & $1 / 4$ & 4.439 & Inconsistent \\
\hline & 9 & $1 / 4$ & 4.708 & Inconsistent \\
\hline \multirow{9}{*}{9} & 1 & $1 / 4$ & 1.659 & Inconsistent \\
\hline & 2 & $1 / 4$ & 2.455 & Inconsistent \\
\hline & 3 & $1 / 4$ & 2.996 & Inconsistent \\
\hline & 4 & $1 / 4$ & 3.424 & Inconsistent \\
\hline & 5 & $1 / 4$ & 3.790 & Inconsistent \\
\hline & 6 & $1 / 4$ & 4.119 & Inconsistent \\
\hline & 7 & $1 / 4$ & 4.423 & Inconsistent \\
\hline & 8 & $1 / 4$ & 4.711 & Inconsistent \\
\hline & 9 & $1 / 4$ & 4.987 & Inconsistent \\
\hline \multirow{9}{*}{1} & 1 & $1 / 5$ & 0.289 & Inconsistent \\
\hline & 2 & $1 / 5$ & 0.608 & Inconsistent \\
\hline & 3 & $1 / 5$ & 0.861 & Inconsistent \\
\hline & 4 & $1 / 5$ & 1.078 & Inconsistent \\
\hline & 5 & $1 / 5$ & 1.274 & Inconsistent \\
\hline & 6 & $1 / 5$ & 1.457 & Inconsistent \\
\hline & 7 & $1 / 5$ & 1.631 & Inconsistent \\
\hline & 8 & $1 / 5$ & 1.798 & Inconsistent \\
\hline & 9 & $1 / 5$ & 1.960 & Inconsistent \\
\hline
\end{tabular}




\begin{tabular}{|c|c|c|c|c|}
\hline \multirow{9}{*}{2} & 1 & $1 / 5$ & 0.613 & Inconsistent \\
\hline & 2 & $1 / 5$ & 1.063 & Inconsistent \\
\hline & 3 & $1 / 5$ & 1.397 & Inconsistent \\
\hline & 4 & $1 / 5$ & 1.677 & Inconsistent \\
\hline & 5 & $1 / 5$ & 1.926 & Inconsistent \\
\hline & 6 & $1 / 5$ & 2.157 & Inconsistent \\
\hline & 7 & $1 / 5$ & 2.375 & Inconsistent \\
\hline & 8 & $1 / 5$ & 2.585 & Inconsistent \\
\hline & 9 & $1 / 5$ & 2.789 & Inconsistent \\
\hline \multirow{9}{*}{3} & 1 & $1 / 5$ & 0.869 & Inconsistent \\
\hline & 2 & $1 / 5$ & 1.400 & Inconsistent \\
\hline & 3 & $1 / 5$ & 1.784 & Inconsistent \\
\hline & 4 & $1 / 5$ & 2.102 & Inconsistent \\
\hline & 5 & $1 / 5$ & 2.383 & Inconsistent \\
\hline & 6 & $1 / 5$ & 2.642 & Inconsistent \\
\hline & 7 & $1 / 5$ & 2.886 & Inconsistent \\
\hline & 8 & $1 / 5$ & 3.120 & Inconsistent \\
\hline & 9 & $1 / 5$ & 3.347 & Inconsistent \\
\hline \multirow{9}{*}{4} & 1 & $1 / 5$ & 1.084 & Inconsistent \\
\hline & 2 & $1 / 5$ & 1.680 & Inconsistent \\
\hline & 3 & $1 / 5$ & 2.102 & Inconsistent \\
\hline & 4 & $1 / 5$ & 2.448 & Inconsistent \\
\hline & 5 & $1 / 5$ & 2.753 & Inconsistent \\
\hline & 6 & $1 / 5$ & 3.032 & Inconsistent \\
\hline & 7 & $1 / 5$ & 3.295 & Inconsistent \\
\hline & 8 & $1 / 5$ & 3.547 & Inconsistent \\
\hline & 9 & $1 / 5$ & 3.790 & Inconsistent \\
\hline \multirow{9}{*}{5} & 1 & $1 / 5$ & 1.274 & Inconsistent \\
\hline & 2 & $1 / 5$ & 1.926 & Inconsistent \\
\hline & 3 & $1 / 5$ & 2.383 & Inconsistent \\
\hline & 4 & $1 / 5$ & 2.753 & Inconsistent \\
\hline & 5 & $1 / 5$ & 3.077 & Inconsistent \\
\hline & 6 & $1 / 5$ & 3.373 & Inconsistent \\
\hline & 7 & $1 / 5$ & 3.650 & Inconsistent \\
\hline & 8 & $1 / 5$ & 3.915 & Inconsistent \\
\hline & 9 & $1 / 5$ & 4.170 & Inconsistent \\
\hline \multirow{9}{*}{6} & 1 & $1 / 5$ & 1.448 & Inconsistent \\
\hline & 2 & $1 / 5$ & 2.152 & Inconsistent \\
\hline & 3 & $1 / 5$ & 2.640 & Inconsistent \\
\hline & 4 & $1 / 5$ & 3.032 & Inconsistent \\
\hline & 5 & $1 / 5$ & 3.373 & Inconsistent \\
\hline & 6 & $1 / 5$ & 3.683 & Inconsistent \\
\hline & 7 & $1 / 5$ & 3.972 & Inconsistent \\
\hline & 8 & $1 / 5$ & 4.248 & Inconsistent \\
\hline & 9 & $1 / 5$ & 4.514 & Inconsistent \\
\hline \multirow{9}{*}{7} & 1 & $1 / 5$ & 1.610 & Inconsistent \\
\hline & 2 & $1 / 5$ & 2.364 & Inconsistent \\
\hline & 3 & $1 / 5$ & 2.881 & Inconsistent \\
\hline & 4 & $1 / 5$ & 3.294 & Inconsistent \\
\hline & 5 & $1 / 5$ & 3.650 & Inconsistent \\
\hline & 6 & $1 / 5$ & 3.973 & Inconsistent \\
\hline & 7 & $1 / 5$ & 4.273 & Inconsistent \\
\hline & 8 & $1 / 5$ & 4.559 & Inconsistent \\
\hline & 9 & $1 / 5$ & 4.833 & Inconsistent \\
\hline \multirow{9}{*}{8} & 1 & $1 / 5$ & 1.763 & Inconsistent \\
\hline & 2 & $1 / 5$ & 2.567 & Inconsistent \\
\hline & 3 & $1 / 5$ & 3.112 & Inconsistent \\
\hline & 4 & $1 / 5$ & 3.544 & Inconsistent \\
\hline & 5 & $1 / 5$ & 3.915 & Inconsistent \\
\hline & 6 & $1 / 5$ & 4.249 & Inconsistent \\
\hline & 7 & $1 / 5$ & 4.559 & Inconsistent \\
\hline & 8 & $1 / 5$ & 4.853 & Inconsistent \\
\hline & 9 & $1 / 5$ & 5.136 & Inconsistent \\
\hline \multirow{9}{*}{9} & 1 & $1 / 5$ & 1.910 & Inconsistent \\
\hline & 2 & $1 / 5$ & 2.762 & Inconsistent \\
\hline & 3 & $1 / 5$ & 3.335 & Inconsistent \\
\hline & 4 & $1 / 5$ & 3.786 & Inconsistent \\
\hline & 5 & $1 / 5$ & 4.170 & Inconsistent \\
\hline & 6 & $1 / 5$ & 4.516 & Inconsistent \\
\hline & 7 & $1 / 5$ & 4.835 & Inconsistent \\
\hline & 8 & $1 / 5$ & 5.137 & Inconsistent \\
\hline & 9 & $1 / 5$ & 5.426 & Inconsistent \\
\hline
\end{tabular}




\begin{tabular}{|c|c|c|c|c|}
\hline \multirow{9}{*}{1} & 1 & $1 / 6$ & 0.364 & Inconsistent \\
\hline & 2 & $1 / 6$ & 0.721 & Inconsistent \\
\hline & 3 & $1 / 6$ & 0.999 & Inconsistent \\
\hline & 4 & $1 / 6$ & 1.235 & Inconsistent \\
\hline & 5 & $1 / 6$ & 1.448 & Inconsistent \\
\hline & 6 & $1 / 6$ & 1.645 & Inconsistent \\
\hline & 7 & $1 / 6$ & 1.831 & Inconsistent \\
\hline & 8 & $1 / 6$ & 2.010 & Inconsistent \\
\hline & 9 & $1 / 6$ & 2.184 & Inconsistent \\
\hline \multirow{9}{*}{2} & 1 & $1 / 6$ & 0.730 & Inconsistent \\
\hline & 2 & $1 / 6$ & 1.224 & Inconsistent \\
\hline & 3 & $1 / 6$ & 1.586 & Inconsistent \\
\hline & 4 & $1 / 6$ & 1.886 & Inconsistent \\
\hline & 5 & $1 / 6$ & 2.152 & Inconsistent \\
\hline & 6 & $1 / 6$ & 2.397 & Inconsistent \\
\hline & 7 & $1 / 6$ & 2.629 & Inconsistent \\
\hline & 8 & $1 / 6$ & 2.851 & Inconsistent \\
\hline & 9 & $1 / 6$ & 3.066 & Inconsistent \\
\hline \multirow{9}{*}{3} & 1 & $1 / 6$ & 1.014 & Inconsistent \\
\hline & 2 & $1 / 6$ & 1.592 & Inconsistent \\
\hline & 3 & $1 / 6$ & 2.004 & Inconsistent \\
\hline & 4 & $1 / 6$ & 2.342 & Inconsistent \\
\hline & 5 & $1 / 6$ & 2.640 & Inconsistent \\
\hline & 6 & $1 / 6$ & 2.913 & Inconsistent \\
\hline & 7 & $1 / 6$ & 3.170 & Inconsistent \\
\hline & 8 & $1 / 6$ & 3.417 & Inconsistent \\
\hline & 9 & $1 / 6$ & 3.655 & Inconsistent \\
\hline \multirow{9}{*}{4} & 1 & $1 / 6$ & 1.250 & Inconsistent \\
\hline & 2 & $1 / 6$ & 1.893 & Inconsistent \\
\hline & 3 & $1 / 6$ & 2.344 & Inconsistent \\
\hline & 4 & $1 / 6$ & 2.711 & Inconsistent \\
\hline & 5 & $1 / 6$ & 3.032 & Inconsistent \\
\hline & 6 & $1 / 6$ & 3.325 & Inconsistent \\
\hline & 7 & $1 / 6$ & 3.601 & Inconsistent \\
\hline & 8 & $1 / 6$ & 3.864 & Inconsistent \\
\hline & 9 & $1 / 6$ & 4.119 & Inconsistent \\
\hline \multirow{9}{*}{5} & 1 & $1 / 6$ & 1.457 & Inconsistent \\
\hline & 2 & $1 / 6$ & 2.157 & Inconsistent \\
\hline & 3 & $1 / 6$ & 2.642 & Inconsistent \\
\hline & 4 & $1 / 6$ & 3.032 & Inconsistent \\
\hline & 5 & $1 / 6$ & 3.373 & Inconsistent \\
\hline & 6 & $1 / 6$ & 3.683 & Inconsistent \\
\hline & 7 & $1 / 6$ & 3.973 & Inconsistent \\
\hline & 8 & $1 / 6$ & 4.249 & Inconsistent \\
\hline & 9 & $1 / 6$ & 4.516 & Inconsistent \\
\hline \multirow{9}{*}{6} & 1 & $1 / 6$ & 1.645 & Inconsistent \\
\hline & 2 & $1 / 6$ & 2.397 & Inconsistent \\
\hline & 3 & $1 / 6$ & 2.913 & Inconsistent \\
\hline & 4 & $1 / 6$ & 3.325 & Inconsistent \\
\hline & 5 & $1 / 6$ & 3.683 & Inconsistent \\
\hline & 6 & $1 / 6$ & 4.006 & Inconsistent \\
\hline & 7 & $1 / 6$ & 4.309 & Inconsistent \\
\hline & 8 & $1 / 6$ & 4.596 & Inconsistent \\
\hline & 9 & $1 / 6$ & 4.873 & Inconsistent \\
\hline \multirow{9}{*}{7} & 1 & $1 / 6$ & 1.610 & Inconsistent \\
\hline & 2 & $1 / 6$ & 2.364 & Inconsistent \\
\hline & 3 & $1 / 6$ & 2.881 & Inconsistent \\
\hline & 4 & $1 / 6$ & 3.294 & Inconsistent \\
\hline & 5 & $1 / 6$ & 3.650 & Inconsistent \\
\hline & 6 & $1 / 6$ & 3.973 & Inconsistent \\
\hline & 7 & $1 / 6$ & 4.273 & Inconsistent \\
\hline & 8 & $1 / 6$ & 4.559 & Inconsistent \\
\hline & 9 & $1 / 6$ & 4.833 & Inconsistent \\
\hline \multirow{9}{*}{8} & 1 & $1 / 6$ & 1.983 & Inconsistent \\
\hline & 2 & $1 / 6$ & 2.836 & Inconsistent \\
\hline & 3 & $1 / 6$ & 3.409 & Inconsistent \\
\hline & 4 & $1 / 6$ & 3.861 & Inconsistent \\
\hline & 5 & $1 / 6$ & 4.248 & Inconsistent \\
\hline & 6 & $1 / 6$ & 4.596 & Inconsistent \\
\hline & 7 & $1 / 6$ & 4.919 & Inconsistent \\
\hline & 8 & $1 / 6$ & 5.224 & Inconsistent \\
\hline & 9 & $1 / 6$ & 5.517 & Inconsistent \\
\hline
\end{tabular}


RJOAS, 3(87), March 2019

\begin{tabular}{|c|c|c|c|c|}
\hline \multirow{9}{*}{9} & 1 & $1 / 6$ & 2.141 & Inconsistent \\
\hline & 2 & $1 / 6$ & 3.042 & Inconsistent \\
\hline & 3 & $1 / 6$ & 3.643 & Inconsistent \\
\hline & 4 & $1 / 6$ & 4.113 & Inconsistent \\
\hline & 5 & $1 / 6$ & 4.514 & Inconsistent \\
\hline & 6 & $1 / 6$ & 4.873 & Inconsistent \\
\hline & 7 & $1 / 6$ & 5.204 & Inconsistent \\
\hline & 8 & $1 / 6$ & 5.517 & Inconsistent \\
\hline & 9 & $1 / 6$ & 5.817 & Inconsistent \\
\hline \multirow{9}{*}{1} & 1 & $1 / 7$ & 0.436 & Inconsistent \\
\hline & 2 & $1 / 7$ & 0.829 & Inconsistent \\
\hline & 3 & $1 / 7$ & 1.130 & Inconsistent \\
\hline & 4 & $1 / 7$ & 1.383 & Inconsistent \\
\hline & 5 & $1 / 7$ & 1.610 & Inconsistent \\
\hline & 6 & $1 / 7$ & 1.819 & Inconsistent \\
\hline & 7 & $1 / 7$ & 2.017 & Inconsistent \\
\hline & 8 & $1 / 7$ & 2.206 & Inconsistent \\
\hline & 9 & $1 / 7$ & 2.389 & Inconsistent \\
\hline \multirow{9}{*}{2} & 1 & $1 / 7$ & 0.843 & Inconsistent \\
\hline & 2 & $1 / 7$ & 1.378 & Inconsistent \\
\hline & 3 & $1 / 7$ & 1.764 & Inconsistent \\
\hline & 4 & $1 / 7$ & 2.083 & Inconsistent \\
\hline & 5 & $1 / 7$ & 2.364 & Inconsistent \\
\hline & 6 & $1 / 7$ & 2.622 & Inconsistent \\
\hline & 7 & $1 / 7$ & 2.865 & Inconsistent \\
\hline & 8 & $1 / 7$ & 3.097 & Inconsistent \\
\hline & 9 & $1 / 7$ & 3.322 & Inconsistent \\
\hline \multirow{9}{*}{3} & 1 & $1 / 7$ & 1.152 & Inconsistent \\
\hline & 2 & $1 / 7$ & 1.774 & Inconsistent \\
\hline & 3 & $1 / 7$ & 2.212 & Inconsistent \\
\hline & 4 & $1 / 7$ & 2.568 & Inconsistent \\
\hline & 5 & $1 / 7$ & 2.881 & Inconsistent \\
\hline & 6 & $1 / 7$ & 3.167 & Inconsistent \\
\hline & 7 & $1 / 7$ & 3.436 & Inconsistent \\
\hline & 8 & $1 / 7$ & 3.692 & Inconsistent \\
\hline & 9 & $1 / 7$ & 3.940 & Inconsistent \\
\hline \multirow{9}{*}{4} & 1 & $1 / 7$ & 1.408 & Inconsistent \\
\hline & 2 & $1 / 7$ & 2.096 & Inconsistent \\
\hline & 3 & $1 / 7$ & 2.573 & Inconsistent \\
\hline & 4 & $1 / 7$ & 2.958 & Inconsistent \\
\hline & 5 & $1 / 7$ & 3.294 & Inconsistent \\
\hline & 6 & $1 / 7$ & 3.600 & Inconsistent \\
\hline & 7 & $1 / 7$ & 3.886 & Inconsistent \\
\hline & 8 & $1 / 7$ & 4.160 & Inconsistent \\
\hline & 9 & $1 / 7$ & 4.423 & Inconsistent \\
\hline \multirow{9}{*}{5} & 1 & $1 / 7$ & 1.631 & Inconsistent \\
\hline & 2 & $1 / 7$ & 2.375 & Inconsistent \\
\hline & 3 & $1 / 7$ & 2.886 & Inconsistent \\
\hline & 4 & $1 / 7$ & 3.295 & Inconsistent \\
\hline & 5 & $1 / 7$ & 3.650 & Inconsistent \\
\hline & 6 & $1 / 7$ & 3.972 & Inconsistent \\
\hline & 7 & $1 / 7$ & 4.273 & Inconsistent \\
\hline & 8 & $1 / 7$ & 4.559 & Inconsistent \\
\hline & 9 & $1 / 7$ & 4.835 & Inconsistent \\
\hline \multirow{9}{*}{6} & 1 & $1 / 7$ & 1.831 & Inconsistent \\
\hline & 2 & $1 / 7$ & 2.629 & Inconsistent \\
\hline & 3 & $1 / 7$ & 3.170 & Inconsistent \\
\hline & 4 & $1 / 7$ & 3.601 & Inconsistent \\
\hline & 5 & $1 / 7$ & 3.973 & Inconsistent \\
\hline & 6 & $1 / 7$ & 4.309 & Inconsistent \\
\hline & 7 & $1 / 7$ & 4.622 & Inconsistent \\
\hline & 8 & $1 / 7$ & 4.919 & Inconsistent \\
\hline & 9 & $1 / 7$ & 5.204 & Inconsistent \\
\hline \multirow{9}{*}{7} & 1 & $1 / 7$ & 2.017 & Inconsistent \\
\hline & 2 & $1 / 7$ & 2.865 & Inconsistent \\
\hline & 3 & $1 / 7$ & 3.436 & Inconsistent \\
\hline & 4 & $1 / 7$ & 3.886 & Inconsistent \\
\hline & 5 & $1 / 7$ & 4.273 & Inconsistent \\
\hline & 6 & $1 / 7$ & 4.622 & Inconsistent \\
\hline & 7 & $1 / 7$ & 4.945 & Inconsistent \\
\hline & 8 & $1 / 7$ & 5.251 & Inconsistent \\
\hline & 9 & $1 / 7$ & 5.546 & Inconsistent \\
\hline
\end{tabular}




\begin{tabular}{|c|c|c|c|c|}
\hline \multirow{9}{*}{8} & 1 & $1 / 7$ & 2.191 & Inconsistent \\
\hline & 2 & $1 / 7$ & 3.089 & Inconsistent \\
\hline & 3 & $1 / 7$ & 3.688 & Inconsistent \\
\hline & 4 & $1 / 7$ & 4.158 & Inconsistent \\
\hline & 5 & $1 / 7$ & 4.559 & Inconsistent \\
\hline & 6 & $1 / 7$ & 4.918 & Inconsistent \\
\hline & 7 & $1 / 7$ & 5.251 & Inconsistent \\
\hline & 8 & $1 / 7$ & 5.566 & Inconsistent \\
\hline & 9 & $1 / 7$ & 5.868 & Inconsistent \\
\hline \multirow{9}{*}{9} & 1 & $1 / 7$ & 2.357 & Inconsistent \\
\hline & 2 & $1 / 7$ & 3.304 & Inconsistent \\
\hline & 3 & $1 / 7$ & 3.930 & Inconsistent \\
\hline & 4 & $1 / 7$ & 4.418 & Inconsistent \\
\hline & 5 & $1 / 7$ & 4.833 & Inconsistent \\
\hline & 6 & $1 / 7$ & 5.204 & Inconsistent \\
\hline & 7 & $1 / 7$ & 5.546 & Inconsistent \\
\hline & 8 & $1 / 7$ & 5.868 & Inconsistent \\
\hline & 9 & $1 / 7$ & 6.177 & Inconsistent \\
\hline \multirow{9}{*}{1} & 1 & $1 / 8$ & 0.507 & Inconsistent \\
\hline & 2 & $1 / 8$ & 0.933 & Inconsistent \\
\hline & 3 & $1 / 8$ & 1.254 & Inconsistent \\
\hline & 4 & $1 / 8$ & 1.524 & Inconsistent \\
\hline & 5 & $1 / 8$ & 1,763 & Inconsistent \\
\hline & 6 & $1 / 8$ & 1.983 & Inconsistent \\
\hline & 7 & $1 / 8$ & 2.191 & Inconsistent \\
\hline & 8 & $1 / 8$ & 2.389 & Inconsistent \\
\hline & 9 & $1 / 8$ & 2.581 & Inconsistent \\
\hline \multirow{9}{*}{2} & 1 & $1 / 8$ & 0.951 & Inconsistent \\
\hline & 2 & $1 / 8$ & 1.526 & Inconsistent \\
\hline & 3 & $1 / 8$ & 1.936 & Inconsistent \\
\hline & 4 & $1 / 8$ & 2.272 & Inconsistent \\
\hline & 5 & $1 / 8$ & 2.567 & Inconsistent \\
\hline & 6 & $1 / 8$ & 2.836 & Inconsistent \\
\hline & 7 & $1 / 8$ & 3.089 & Inconsistent \\
\hline & 8 & $1 / 8$ & 3.330 & Inconsistent \\
\hline & 9 & $1 / 8$ & 3.563 & Inconsistent \\
\hline \multirow{9}{*}{3} & 1 & $1 / 8$ & 1.286 & Inconsistent \\
\hline & 2 & $1 / 8$ & 1.949 & Inconsistent \\
\hline & 3 & $1 / 8$ & 2.412 & Inconsistent \\
\hline & 4 & $1 / 8$ & 2.786 & Inconsistent \\
\hline & 5 & $1 / 8$ & 3.112 & Inconsistent \\
\hline & 6 & $1 / 8$ & 3.409 & Inconsistent \\
\hline & 7 & $1 / 8$ & 3.688 & Inconsistent \\
\hline & 8 & $1 / 8$ & 3.953 & Inconsistent \\
\hline & 9 & $1 / 8$ & 4.209 & Inconsistent \\
\hline \multirow{9}{*}{4} & 1 & $1 / 8$ & 1.561 & Inconsistent \\
\hline & 2 & $1 / 8$ & 2.291 & Inconsistent \\
\hline & 3 & $1 / 8$ & 2.792 & Inconsistent \\
\hline & 4 & $1 / 8$ & 3.194 & Inconsistent \\
\hline & 5 & $1 / 8$ & 3.544 & Inconsistent \\
\hline & 6 & $1 / 8$ & 3.861 & Inconsistent \\
\hline & 7 & $1 / 8$ & 4.158 & Inconsistent \\
\hline & 8 & $1 / 8$ & 4.439 & Inconsistent \\
\hline & 9 & $1 / 8$ & 4.711 & Inconsistent \\
\hline \multirow{9}{*}{5} & 1 & $1 / 8$ & 1.798 & Inconsistent \\
\hline & 2 & $1 / 8$ & 2.585 & Inconsistent \\
\hline & 3 & $1 / 8$ & 3.120 & Inconsistent \\
\hline & 4 & $1 / 8$ & 3.547 & Inconsistent \\
\hline & 5 & $1 / 8$ & 3.915 & Inconsistent \\
\hline & 6 & $1 / 8$ & 4.248 & Inconsistent \\
\hline & 7 & $1 / 8$ & 4.559 & Inconsistent \\
\hline & 8 & $1 / 8$ & 4.853 & Inconsistent \\
\hline & 9 & $1 / 8$ & 5.137 & Inconsistent \\
\hline \multirow{9}{*}{6} & 1 & $1 / 8$ & 2.010 & Inconsistent \\
\hline & 2 & $1 / 8$ & 2.851 & Inconsistent \\
\hline & 3 & $1 / 8$ & 3.417 & Inconsistent \\
\hline & 4 & $1 / 8$ & 3.864 & Inconsistent \\
\hline & 5 & $1 / 8$ & 4.249 & Inconsistent \\
\hline & 6 & $1 / 8$ & 4.596 & Inconsistent \\
\hline & 7 & $1 / 8$ & 4.918 & Inconsistent \\
\hline & 8 & $1 / 8$ & 5.224 & Inconsistent \\
\hline & 9 & $1 / 8$ & 5.517 & Inconsistent \\
\hline
\end{tabular}




\begin{tabular}{|c|c|c|c|c|}
\hline \multirow{9}{*}{7} & 1 & $1 / 8$ & 2.206 & Inconsistent \\
\hline & 2 & $1 / 8$ & 3.097 & Inconsistent \\
\hline & 3 & $1 / 8$ & 3.692 & Inconsistent \\
\hline & 4 & $1 / 8$ & 4.160 & Inconsistent \\
\hline & 5 & $1 / 8$ & 4.559 & Inconsistent \\
\hline & 6 & $1 / 8$ & 4.919 & Inconsistent \\
\hline & 7 & $1 / 8$ & 5.251 & Inconsistent \\
\hline & 8 & $1 / 8$ & 5.566 & Inconsistent \\
\hline & 9 & $1 / 8$ & 5.868 & Inconsistent \\
\hline \multirow{9}{*}{8} & 1 & $1 / 8$ & 2.389 & Inconsistent \\
\hline & 2 & $1 / 8$ & 3.330 & Inconsistent \\
\hline & 3 & $1 / 8$ & 3.953 & Inconsistent \\
\hline & 4 & $1 / 8$ & 4.439 & Inconsistent \\
\hline & 5 & $1 / 8$ & 4.853 & Inconsistent \\
\hline & 6 & $1 / 8$ & 5.224 & Inconsistent \\
\hline & 7 & $1 / 8$ & 5.566 & Inconsistent \\
\hline & 8 & $1 / 8$ & 5.889 & Inconsistent \\
\hline & 9 & $1 / 8$ & 6.199 & Inconsistent \\
\hline \multirow{9}{*}{9} & 1 & $1 / 8$ & 2.563 & Inconsistent \\
\hline & 2 & $1 / 8$ & 3.553 & Inconsistent \\
\hline & 3 & $1 / 8$ & 4.203 & Inconsistent \\
\hline & 4 & $1 / 8$ & 4.708 & Inconsistent \\
\hline & 5 & $1 / 8$ & 5.136 & Inconsistent \\
\hline & 6 & $1 / 8$ & 5.517 & Inconsistent \\
\hline & 7 & $1 / 8$ & 5.868 & Inconsistent \\
\hline & 8 & $1 / 8$ & 6.199 & Inconsistent \\
\hline & 9 & $1 / 8$ & 6.515 & Inconsistent \\
\hline \multirow{9}{*}{1} & 1 & $1 / 9$ & 0.576 & Inconsistent \\
\hline & 2 & $1 / 9$ & 1.033 & Inconsistent \\
\hline & 3 & $1 / 9$ & 1.375 & Inconsistent \\
\hline & 4 & $1 / 9$ & 1.659 & Inconsistent \\
\hline & 5 & $1 / 9$ & 1.910 & Inconsistent \\
\hline & 6 & $1 / 9$ & 2.141 & Inconsistent \\
\hline & 7 & $1 / 9$ & 2.357 & Inconsistent \\
\hline & 8 & $1 / 9$ & 2.563 & Inconsistent \\
\hline & 9 & $1 / 9$ & 2.762 & Inconsistent \\
\hline \multirow{9}{*}{2} & 1 & $1 / 9$ & 1.057 & Inconsistent \\
\hline & 2 & $1 / 9$ & 1.670 & Inconsistent \\
\hline & 3 & $1 / 9$ & 2.103 & Inconsistent \\
\hline & 4 & $1 / 9$ & 2.455 & Inconsistent \\
\hline & 5 & $1 / 9$ & 2.762 & Inconsistent \\
\hline & 6 & $1 / 9$ & 3.042 & Inconsistent \\
\hline & 7 & $1 / 9$ & 3.304 & Inconsistent \\
\hline & 8 & $1 / 9$ & 3.553 & Inconsistent \\
\hline & 9 & $1 / 9$ & 3.793 & Inconsistent \\
\hline \multirow{9}{*}{3} & 1 & $1 / 9$ & 1.417 & Inconsistent \\
\hline & 2 & $1 / 9$ & 2.120 & Inconsistent \\
\hline & 3 & $1 / 9$ & 2.606 & Inconsistent \\
\hline & 4 & $1 / 9$ & 2.996 & Inconsistent \\
\hline & 5 & $1 / 9$ & 3.335 & Inconsistent \\
\hline & 6 & $1 / 9$ & 3.643 & Inconsistent \\
\hline & 7 & $1 / 9$ & 3.930 & Inconsistent \\
\hline & 8 & $1 / 9$ & 4.203 & Inconsistent \\
\hline & 9 & $1 / 9$ & 4.466 & Inconsistent \\
\hline \multirow{9}{*}{4} & 1 & $1 / 9$ & 1.709 & Inconsistent \\
\hline & 2 & $1 / 9$ & 2.480 & Inconsistent \\
\hline & 3 & $1 / 9$ & 3.005 & Inconsistent \\
\hline & 4 & $1 / 9$ & 3.424 & Inconsistent \\
\hline & 5 & $1 / 9$ & 3.786 & Inconsistent \\
\hline & 6 & $1 / 9$ & 4.113 & Inconsistent \\
\hline & 7 & $1 / 9$ & 4.418 & Inconsistent \\
\hline & 8 & $1 / 9$ & 4.708 & Inconsistent \\
\hline & 9 & $1 / 9$ & 4.987 & Inconsistent \\
\hline \multirow{9}{*}{5} & 1 & $1 / 9$ & 1.960 & Inconsistent \\
\hline & 2 & $1 / 9$ & 2.789 & Inconsistent \\
\hline & 3 & $1 / 9$ & 3.347 & Inconsistent \\
\hline & 4 & $1 / 9$ & 3.790 & Inconsistent \\
\hline & 5 & $1 / 9$ & 4.170 & Inconsistent \\
\hline & 6 & $1 / 9$ & 4.514 & Inconsistent \\
\hline & 7 & $1 / 9$ & 4.833 & Inconsistent \\
\hline & 8 & $1 / 9$ & 5.136 & Inconsistent \\
\hline & 9 & $1 / 9$ & 5.426 & Inconsistent \\
\hline
\end{tabular}


RJOAS, 3(87), March 2019

\begin{tabular}{|c|c|c|c|c|}
\hline \multirow{9}{*}{6} & 1 & $1 / 9$ & 2.184 & Inconsistent \\
\hline & 2 & $1 / 9$ & 3.066 & Inconsistent \\
\hline & 3 & $1 / 9$ & 3.655 & Inconsistent \\
\hline & 4 & $1 / 9$ & 4.119 & Inconsistent \\
\hline & 5 & $1 / 9$ & 4.516 & Inconsistent \\
\hline & 6 & $1 / 9$ & 4.873 & Inconsistent \\
\hline & 7 & $1 / 9$ & 5.204 & Inconsistent \\
\hline & 8 & $1 / 9$ & 5.517 & Inconsistent \\
\hline & 9 & $1 / 9$ & 5.817 & Inconsistent \\
\hline \multirow{9}{*}{7} & 1 & $1 / 9$ & 2.389 & Inconsistent \\
\hline & 2 & $1 / 9$ & 3.322 & Inconsistent \\
\hline & 3 & $1 / 9$ & 3.940 & Inconsistent \\
\hline & 4 & $1 / 9$ & 4.423 & Inconsistent \\
\hline & 5 & $1 / 9$ & 4.835 & Inconsistent \\
\hline & 6 & $1 / 9$ & 5.204 & Inconsistent \\
\hline & 7 & $1 / 9$ & 5.546 & Inconsistent \\
\hline & 8 & $1 / 9$ & 5.868 & Inconsistent \\
\hline & 9 & $1 / 9$ & 6.177 & Inconsistent \\
\hline \multirow{9}{*}{8} & 1 & $1 / 9$ & 2.581 & Inconsistent \\
\hline & 2 & $1 / 9$ & 3.563 & Inconsistent \\
\hline & 3 & $1 / 9$ & 4.209 & Inconsistent \\
\hline & 4 & $1 / 9$ & 4.711 & Inconsistent \\
\hline & 5 & $1 / 9$ & 5.137 & Inconsistent \\
\hline & 6 & $1 / 9$ & 5.517 & Inconsistent \\
\hline & 7 & $1 / 9$ & 5.868 & Inconsistent \\
\hline & 8 & $1 / 9$ & 6.199 & Inconsistent \\
\hline & 9 & $1 / 9$ & 6.515 & Inconsistent \\
\hline \multirow{9}{*}{9} & 1 & $1 / 9$ & 2.762 & Inconsistent \\
\hline & 2 & $1 / 9$ & 3.793 & Inconsistent \\
\hline & 3 & $1 / 9$ & 4.466 & Inconsistent \\
\hline & 4 & $1 / 9$ & 4.987 & Inconsistent \\
\hline & 5 & $1 / 9$ & 5.426 & Inconsistent \\
\hline & 6 & $1 / 9$ & 5.817 & Inconsistent \\
\hline & 7 & $1 / 9$ & 6.177 & Inconsistent \\
\hline & 8 & $1 / 9$ & 6.515 & Inconsistent \\
\hline & 9 & $1 / 9$ & 6.838 & Inconsistent \\
\hline
\end{tabular}

